DOE/PC/95231-4

DIST. CATEGORY UC-112

UTSI $\quad 96-03$

\title{
NITROGEN OXIDE EMISSIONS FROM COAL FIRED MHD PLANTS
}

TOPICAL REPORT

Edited by:

James N. Chapman

The University of Tennessee Space Institute

Energy Conversion Research \& Development Programs

Tullahoma, Tennessee $\quad 37388-8897$

\section{For}

THE UNITED STATES DEPARTMENT OF ENERGY

Under Contract No. DE-AC22-95PC95231

March 1996 


\section{DISCLAIMER}

This report was prepared as an account of work sponsored by an agency of the United States Government. Neither the United States Government nor any agency thereof, nor any of their employees, makes any warranty, express or implied, or assumes any legal liability or responsibility for the accuracy, completeness, or usefulness of any information, apparatus, product, or process disclosed, or represents that its use would not infringe privately owned rights. Reference herein to any specific commercial product, process, or service by trade name, trademark, manufacturer, or otherwise does not necessarily constitute or imply its endorsement, recommendation, or favoring by the United States Government or any agency thereof. The views and opinions of authors expressed herein do not necessarily state or reflect those of the United States Government or any agency thereof. 


\section{TABLEOFCONTENTS}

PAGE

ABSTRACT .vi

CHAPTER 1 GENERALNATUREOFNOX EMISSIONS

$1.0 \quad$ INTRODUCTION................................................................................................................ 1

1.1 The MHD-Steam Combined Cycle Power Plant............................................................. 1

1.2 General Nature of the Nitrogen Oxide Problem...........................................................1 CHAPTER 2 THE NOX EXPERIMENTS

2.1 The Low Mass Flow (LMF) Train.............................................................................11

2.2 Measurement Methodology..........................................................................................12

$2.3 \quad \mathrm{NO}_{\mathrm{x}}$ Sampling Locations...............................................................................................12

2.3.1 The LMFO Test..........................................................................................................12

2.3.2 LMF1 Tests.......................................................................................................12

2.3.3 LMF 2 \& 4 Tests..........................................................................................................20

2.3.4 LMF5 Tests........................................................................................................................20

CHAPTER 3 NUMERICAL MODELING OFNITROGEN OXIDE DECOMPOSITION

CHAPTER 4 NITROGEN OXIDE EMISSIONISSUES FOR PLANT DESIGN

4.1 Parametric Studies..............................................................................................34

4.2 Minimization Study......................................................................................................40

4.3 Multi-Dimensional Modeling.........................................................................................40

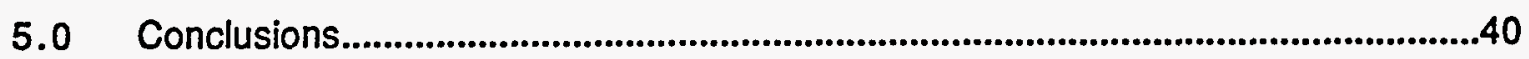

REFERENCES................................................................................................................................43 


\section{LST OF FIGURES}

PAGE

1.1-1 Schematic of MHD/Steam Power Plant.......................................................................2

1.2-1 Combustor Temperature vs. Oxidant Ratio...............................................................3

1.2-2 Combustor $\mathrm{NO}_{x}$ vs. Oxidant Ratio...............................................................................4

1.2-3 $\mathrm{NO}_{x}$ at Radiant Boiler Exit vs. Oxidant Ratio...........................................................5

1.2 -4 Combustor Plasma Conductivity vs. Oxidant Ratio.....................................................7

1.2-5 Conductivity at Channel Entrance vs. Oxidant Ratio................................................8

1.2-6 Overall Efficiency vs. Primary Stoichiometry.........................................................9

1.2-7 $\mathrm{NO}_{x}$ at Cyclone Exit vs. Oxidant Ratio......................................................................10

2.3.1-1 LMF-O Test Train Configuration.............................................................................13

2.3.1-2 $\mathrm{NO}_{x}$ in Radiant Furnace vs. Mass Flow..................................................................14

2.3.1-3 $\mathrm{NO}_{x}$ at Stack vs. Mass Flow Rate............................................................................15

2.3.2-1 Summary of Gas Analysis Operation in LMF1 .......................................................16

2.3.2-2 Stoichiometry NO vs. Stoichiometry..........................................................................17

3.2.3 $\quad \mathrm{NO}_{2}$ and $\mathrm{N}_{2} \mathrm{O}$ (Equivalent) Levels at Radiant Furnace Inlet.................................19

2.3.3-1 Gas Analysis Instrumentation Locations for the LMF3 Series.............................21

2.3.3-2 LMF4 Test Train Configuration................................................................................22

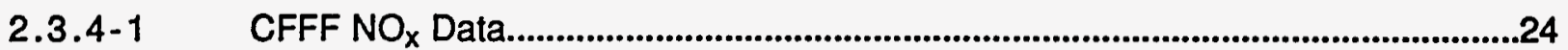

3.1 Calculated and Experimental NO Levels in CFFF Flow Train...............................30

3.2 Calculated and Experimental NO Levels in the CFFF Flow Train..........................31

3.3 Calculated and Experimental NO Levels in the CFFF Flow Train..........................32

4.1-1 Parametric Study, $\mathrm{NO}_{x}$ Emissions....................................................................37

4.1-2 Parametric Study, $\mathrm{NO}_{x}$ Emissions........................................................................38 
4.1-3 Parametric Study, $\mathrm{NO}_{x}$ Emissions.................................................................39

4.2-1 Effects of Cooling Rate and $\mathrm{SCl}$ Temperature on $\mathrm{NO}_{\mathrm{x}}$ Emissions........................41

4.3-1 Spatial Character of Computed CFFF Radiant Furnace NO Decomposition.........42 


\section{LST OF TABLES}

PAGE

$2.1-1$

CFFF LMF TEST TRAIN CONFIGURATIONS. .11

2.3.2-1

GAS ANALYSIS - LMF1-C TESTS. .18

3.1 KINETIC REACTION DATA.. .26

$4.1-1$ PARAMETRIC STUDY OF EXIT COOUNG RATES IN THERADIANT FURNACE ON NOX EMISSIONS. .36 


\title{
FOREWORD
}

This report is a compilation of relevant reports and technical papers previously published. Most of this work, especially the calculational work was performed by the late Professor Lloyd W. Crawford and is hereby so acknowledged. Portions of the text and many of the illustrations are extracted and quoted from the referenced works of Dr. Crawford.

The reader is also referred to a topical thesis report by Mr. Xiaoliang Lu which was supervised by Dr. Crawford and contains both the experimental and modeling treatment of $\mathrm{NO}_{\mathrm{x}}$ for a single MHD POC Test, LMF5-J. That report is "Parameters Affecting Nitrogen Oxides in a Coal-Fired Flow Facility System", DOE/PC/95231-3, dated March 1996.

\begin{abstract}
In this topical report, the nitrogen oxide emission issues from a coal fired MHD steam combined cycle power plant are summarized, both from an experimental and theoretical/calculational viewpoint. The concept of staging the coal combustion to minimize $\mathrm{NO}_{\mathbf{x}}$ is described. The impact of $\mathrm{NO}_{x}$ control design choices on electrical conductivity and overall plant efficiency are described. The results of the $\mathrm{NO}_{x}$ measurements in over 3,000 hours of coal fired testing are summarized. A chemical kinetics model that was used to model the $\mathrm{NO}_{\mathrm{x}}$ decomposition is described. Finally, optimum design choices for a low $\mathrm{NO}_{x}$ plant are discussed and it is shown that the MHD Steam Coal Fired Combined Cycle Power Plant can be designed to operate with $\mathrm{NO}_{x}$ emissions less than $0.05 \mathrm{lbm} / \mathrm{MMBTU}$.
\end{abstract}




\section{CHAPTER 1}

\section{GENERALNATURE OF NOX EMISSIONS}

\subsection{INTRODUCTION}

\subsection{The MHD-Steam Combined Cycle Power Plant}

The prototypical application of MHD to central power generation is in a combined cycle with an MHD generator topping cycle and a steam bottoming cycle. The generic concept for this type plant is shown in Figure 1.1-1.1 The coal is burned at high temperature (around 2900K or $4760^{\circ} \mathrm{F}$ ) with a potassium seed to produce an electrically conducting gas that is needed for efficient MHD power generation. Once the gases cool to the level where equilibrium ionization is too low for efficient MHD power generation (around $2200 \mathrm{~K}, 3500^{\circ} \mathrm{F}$ ), they are exhausted to a furnace through a diffuser for use in generation of additional power via a steam Rankine cycle. The topping and bottoming cycles are inter-related in a number of ways, of course, including heating air for the primary combustor, integration of topping cycle cooling water into the steam circuit, extraction of energy for coal drying, extraction of steam for compressor drives and extraction of steam for drying regenerated potassium seed.

\subsection{General Nature of the Nitrogen Oxide Problem}

The MHD primary combustor operates at higher temperature than other existing and proposed coal fired power plants. Since the formation of nitrogen oxides is known to be higher at higher temperatures, this was considered a substantial problem for the development of environmentally acceptable MHD power plant technology. Figure 1.2-1 shows the typical MHD combustion temperatures as a function of stoichiometry. Stoichiometry is defined in this report as the ratio of the amount of oxygen present to the theoretical amount required for complete oxidation of the fuel reactants. As expected, the temperatures peak at fuel rich conditions, stoichiometry about $90 \%$. The level of nitrogen oxides formed (actually almost exclusively NO in the fuel rich condition) is shown in Figure 1.2-2. Note that the amount of $\mathrm{NO}_{x}$ formed is not a strong function of pressure, but is a strong function of stoichiometry. $\mathrm{NO}_{\mathrm{x}}$ emission standards in the United States are specified in lbm/million Btu at the exhaust stack. The weight of emitted $\mathrm{NO}_{x}$ is based on the fact that $\mathrm{NO}$ is further oxidized to $\mathrm{NO}_{2}$ when the combustion is completed. The New Source Performance Standards (NSPS) level that was in effect for many years was 0.6 $\mathrm{lbm} / \mathrm{MMBTU}$. (There is currently a new standard that lowers this to 0.5 or $0.45 \mathrm{lbm} / \mathrm{MMBTU}$ as dictated by the Clean Air Act Amendments of 1990). The $0.6 \mathrm{lbm} / \mathrm{MMBTU}$ corresponds to about $600 \mathrm{ppm}$ versus the up to $12,000 \mathrm{ppm}$ formed in the primary combustor. The $\mathrm{NO}_{\mathrm{x}}$ control concept developed to solve this problem involves burning the primary combustor fuel rich, allowing the $\mathrm{NO}_{x}$ to decompose in a radiant furnace as the gas cools and performing the secondary combustion at a temperature and in such a way that little additional $\mathrm{NO}_{\mathrm{x}}$ is formed. This is the concept that was developed and proven for use in the design of the Low Mass Flow Train in the DOE Coal Fired Flow Facility (CFFF).

Figure 1.2-3 shows the calculated equilibrium $\mathrm{NO}_{x}$ at the radiant furnace outlet as a function of primary stoichiometry for various secondary combustor gas inlet temperatures. Note the strong dependence on primary stoichiometry and gas temperature entering the secondary combustor, but that very low values seem possible with design control of these 


\section{MagnetoHydroDynamics}

\section{Electric Power Plant}

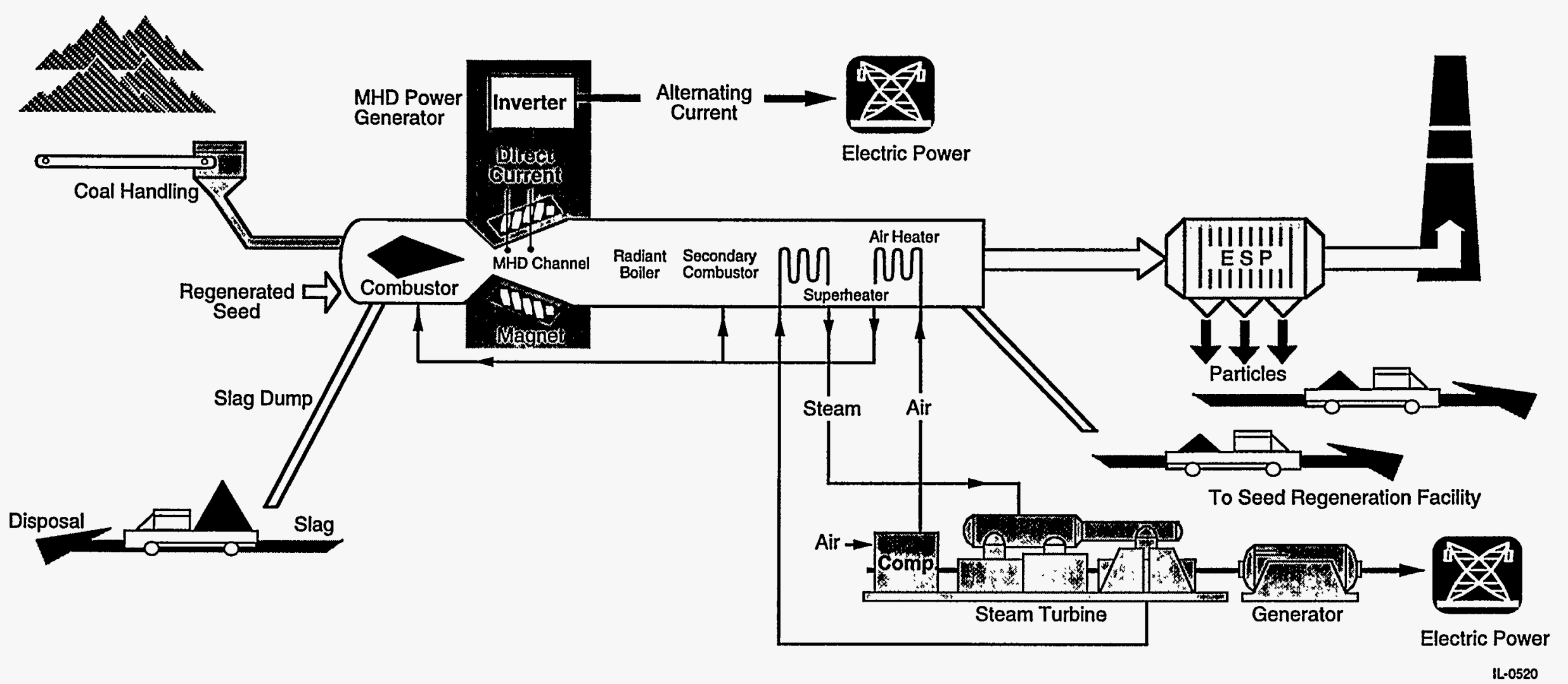

Schematic of MHD/Steam Power Plant

FIGURE 1.1-1 


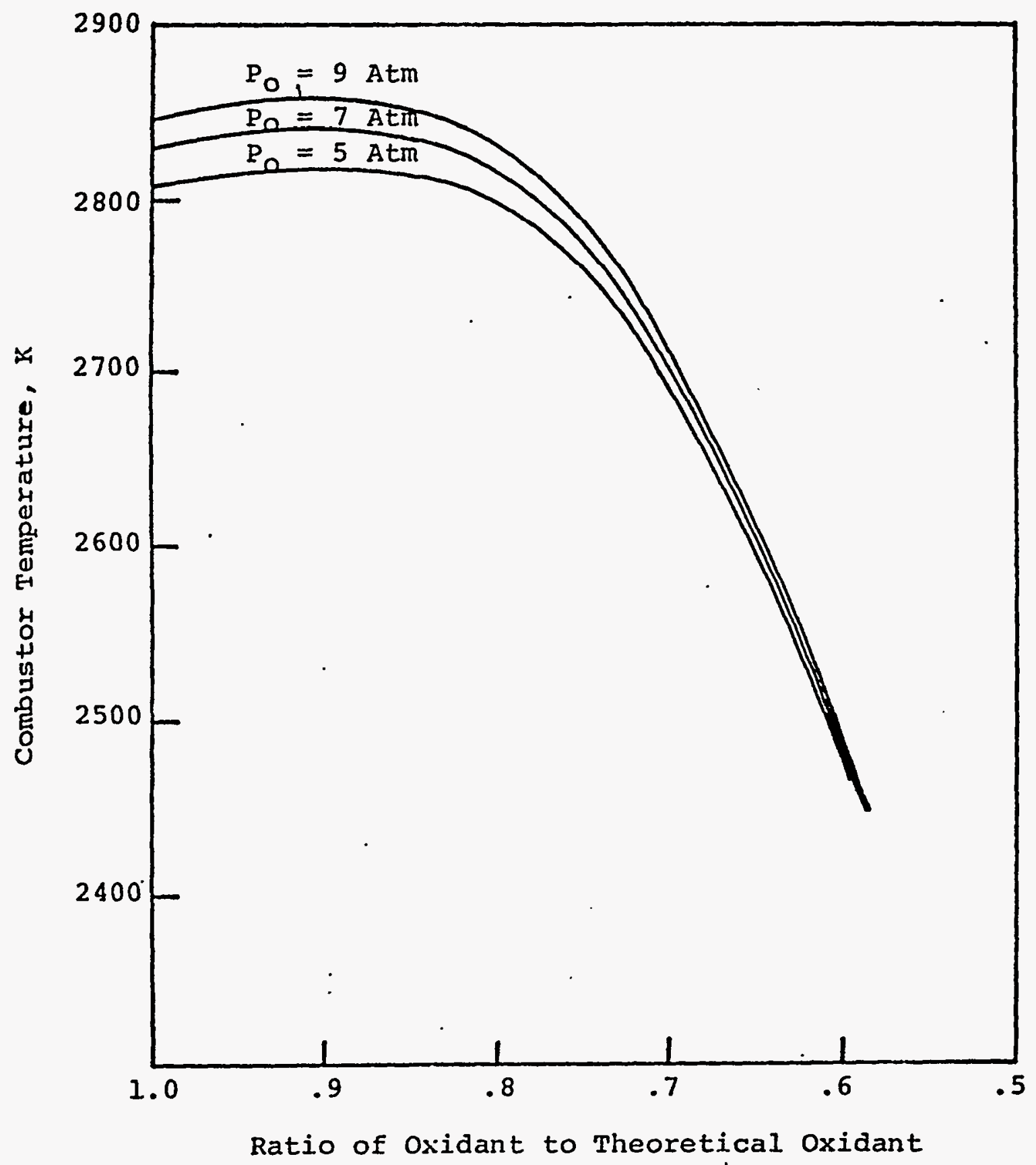

Figure 1.2-1 Combustor Temperature versus Oxidant Ratio. Air Preheated to $1800 \mathrm{~K}$. Illinois $\$ 6 \mathrm{Coal}$ Dried to 2 Percent Moisture. One Percent of Coal HHV Lost from Combustor. 


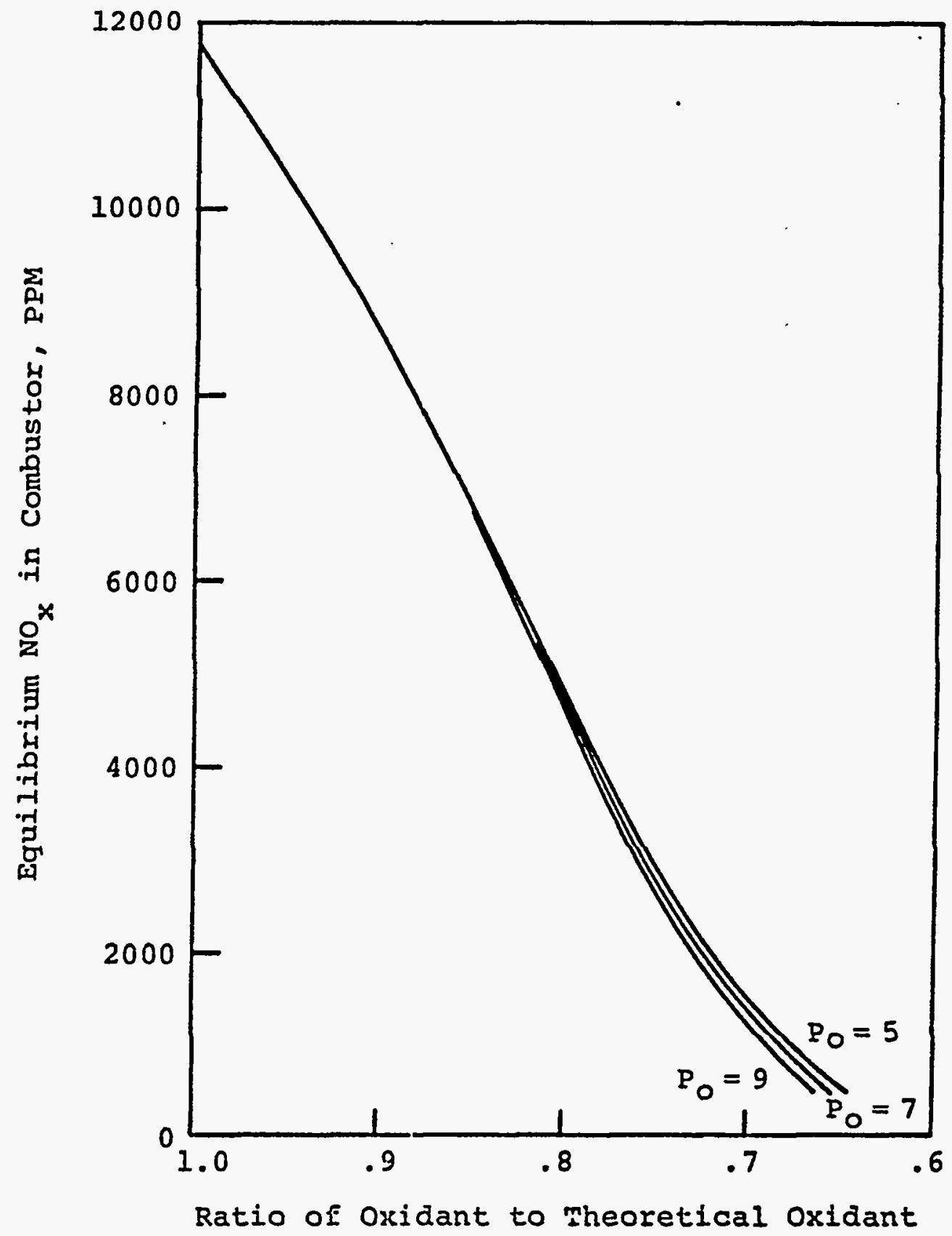

Figure 1.2-2 Combustor $\mathrm{NO}_{\mathrm{x}}$ Versus Oxidant Ratio. 


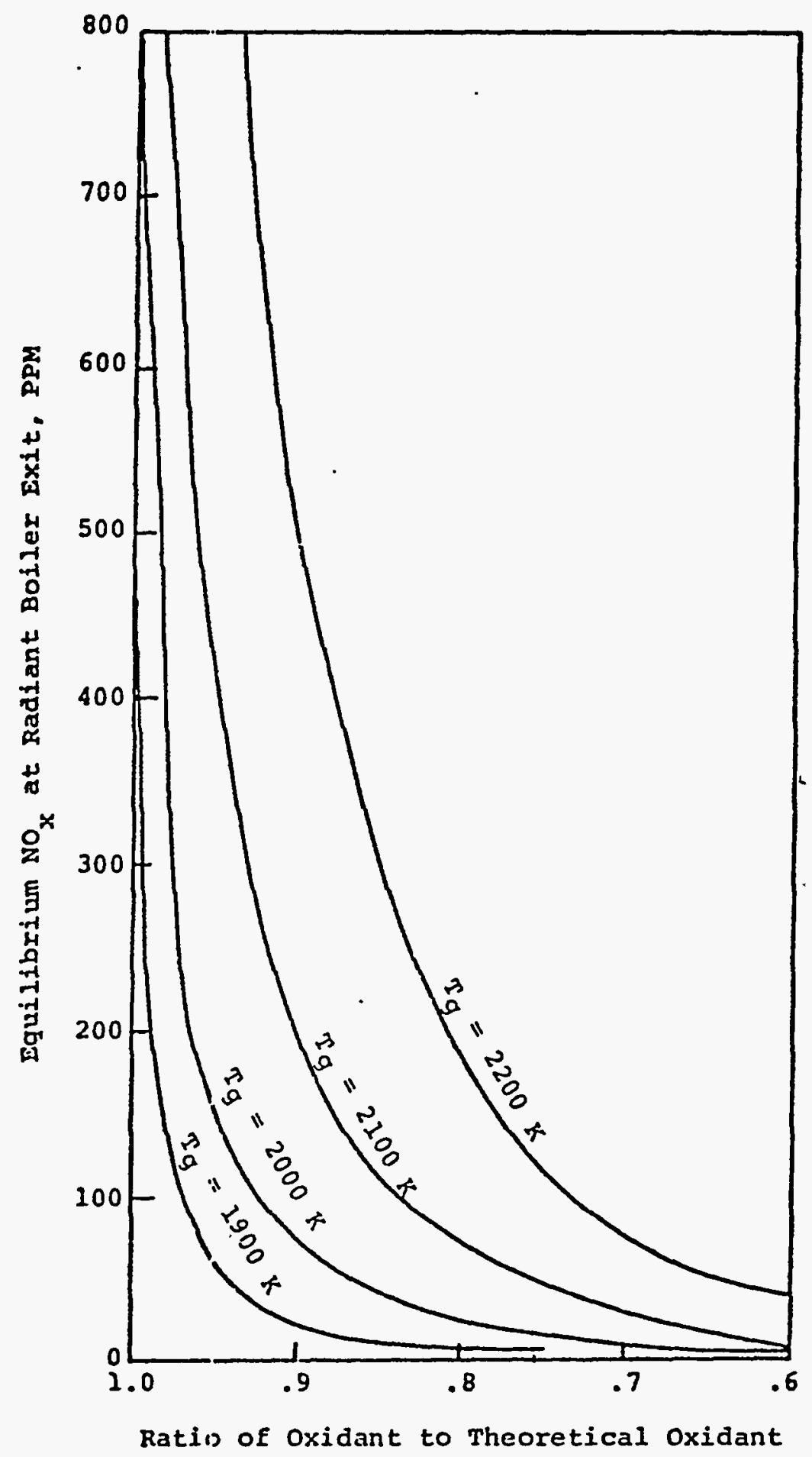

Figure 1.2-3 $\mathrm{NO}_{\mathrm{x}}$ at Radiant Boiler Exit Versus Oxidant Ratio. $\mathrm{P}=1.2 \mathrm{~atm}$ 
variables. A critical issue related to these design choices is how they affect the performance of the plant. One of the principal needs for the topping cycle performance is electrical conductivity of the gas in the MHD generator. The effect of primary stoichiometry on conductivity is shown in Figure 1.2-4 for the primary combustor and in Figure 1.2-5 for the MHD generator entrance, assuming an isentropic expansion to Mach No. 0.9. These calculations show that operation at stoichiometries around 0.85 would be optimum for electrical conductivity and are very favorable for $\mathrm{NO}_{x}$ control. However, there is a performance issue in choosing this stoichiometry since a lower value implies a lower mass flow and thermal input to the more efficient topping cycle and a higher input to the less efficient steam bottoming cycle. Thus, lower stoichiometries tend to reduce overall plant efficiencies. This was studied 3 and Figure 1.2-6 shows the overall plant efficiency variation as a function of primary stoichiometry. Capital costs increase with increasing stoichiometry, however, and the most economical design point depends on the fuel price. The study concluded that the stoichiometry should be chosen primarily to meet the $\mathrm{NO}_{x}$ emission criterion.

Prior to finalizing the design of the LMF furnace and secondary combustor, $\mathrm{NO}_{\mathrm{x}}$ measurements were made in the UTSI laboratory (the Cell III apparatus that was used to develop the design data for the steam bottoming plant simulator) as a function of stoichiometry. The data are shown in Figure 1.2-74 and generally confirm the nature of the equilibrium calculations of Figure 1.2-3 although there was insufficient residence time in this test cell to approach equilibrium at the higher stoichiometries. Pepper 5 also found primary stoichiometry in the upper $80 \%$ range was most economical and reduced $\mathrm{NO}_{\mathrm{x}}$, but he was advised to use a higher primary stoichiometry to reduce corrosion in the radiant furnace. The UTSI design used studded, refractory covered walls to eliminate this corrosion problem. 


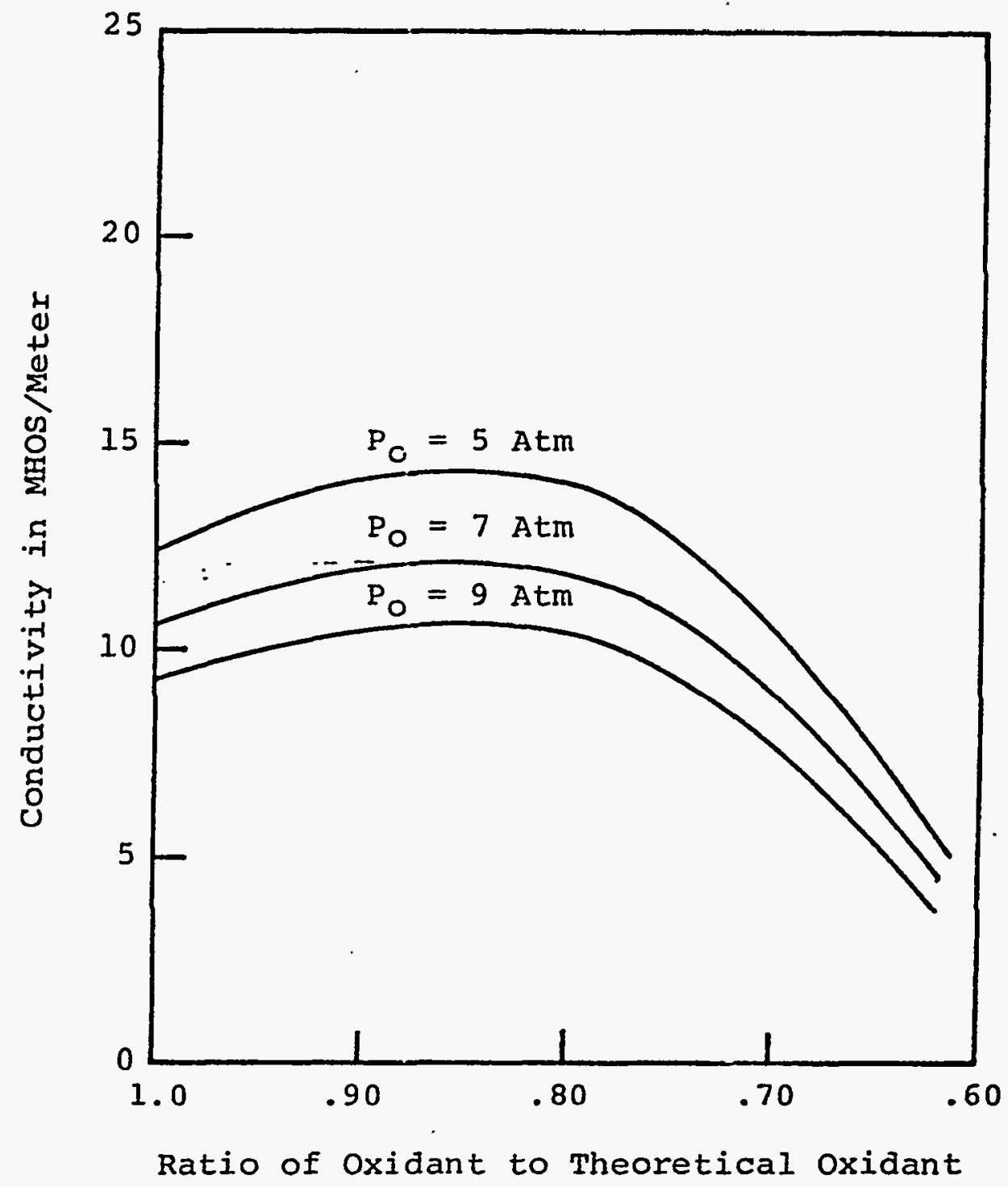

Eigure 1.2-4 Combustor Plasma Conductivity Versus Oxidant Ratio. Air Preheated to $1800 \mathrm{~K}$. Illinois \#6 Coal Dried to 2 Percent Moisture. One Percent of Coal HHV Lost from Combustor. 


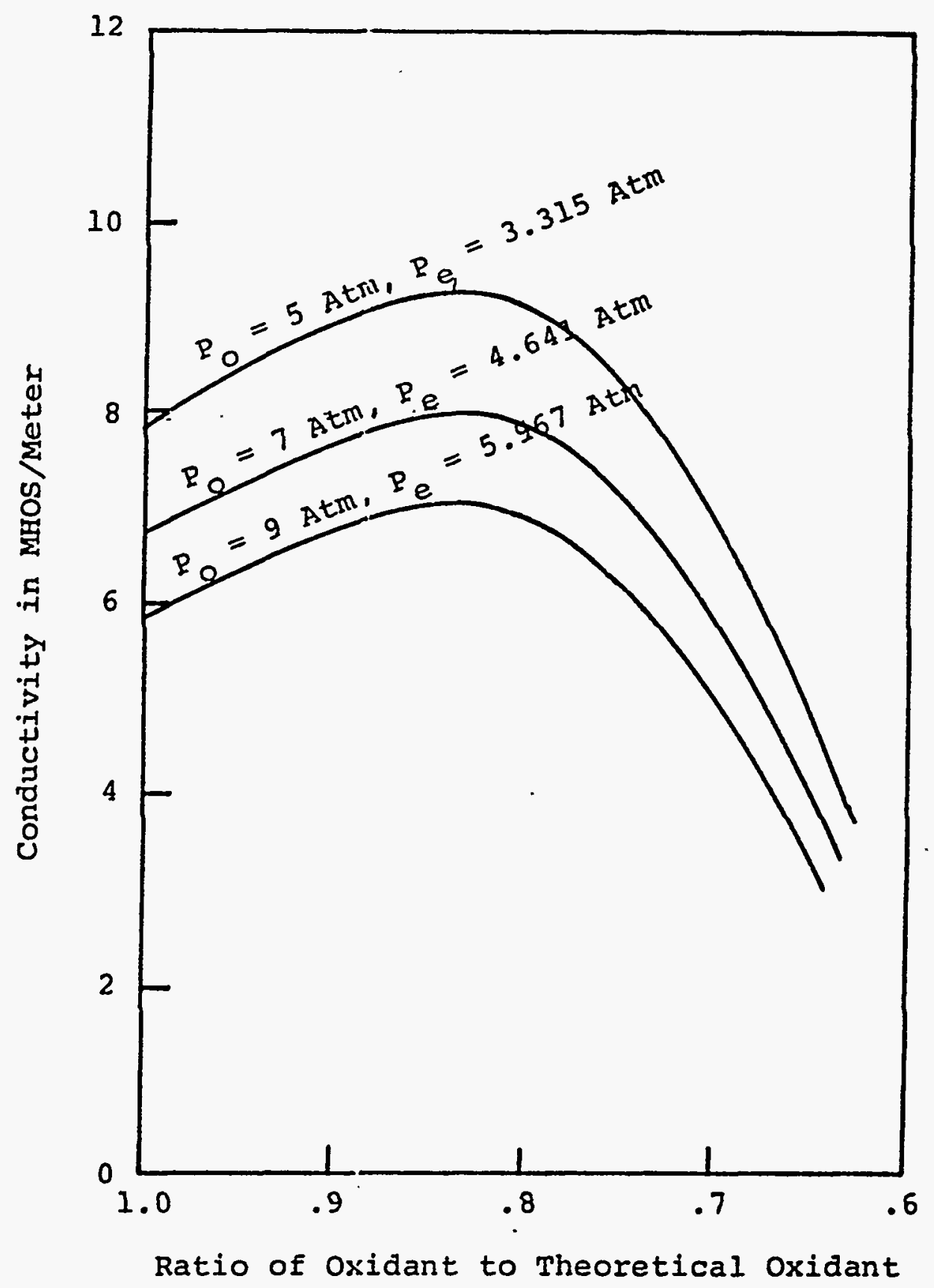

Figure 1.2-5 Conductivity at Channel Entrance Versus Oxidant Ratio.

Entrance Mach No. $=.9, \gamma=1.18$. 


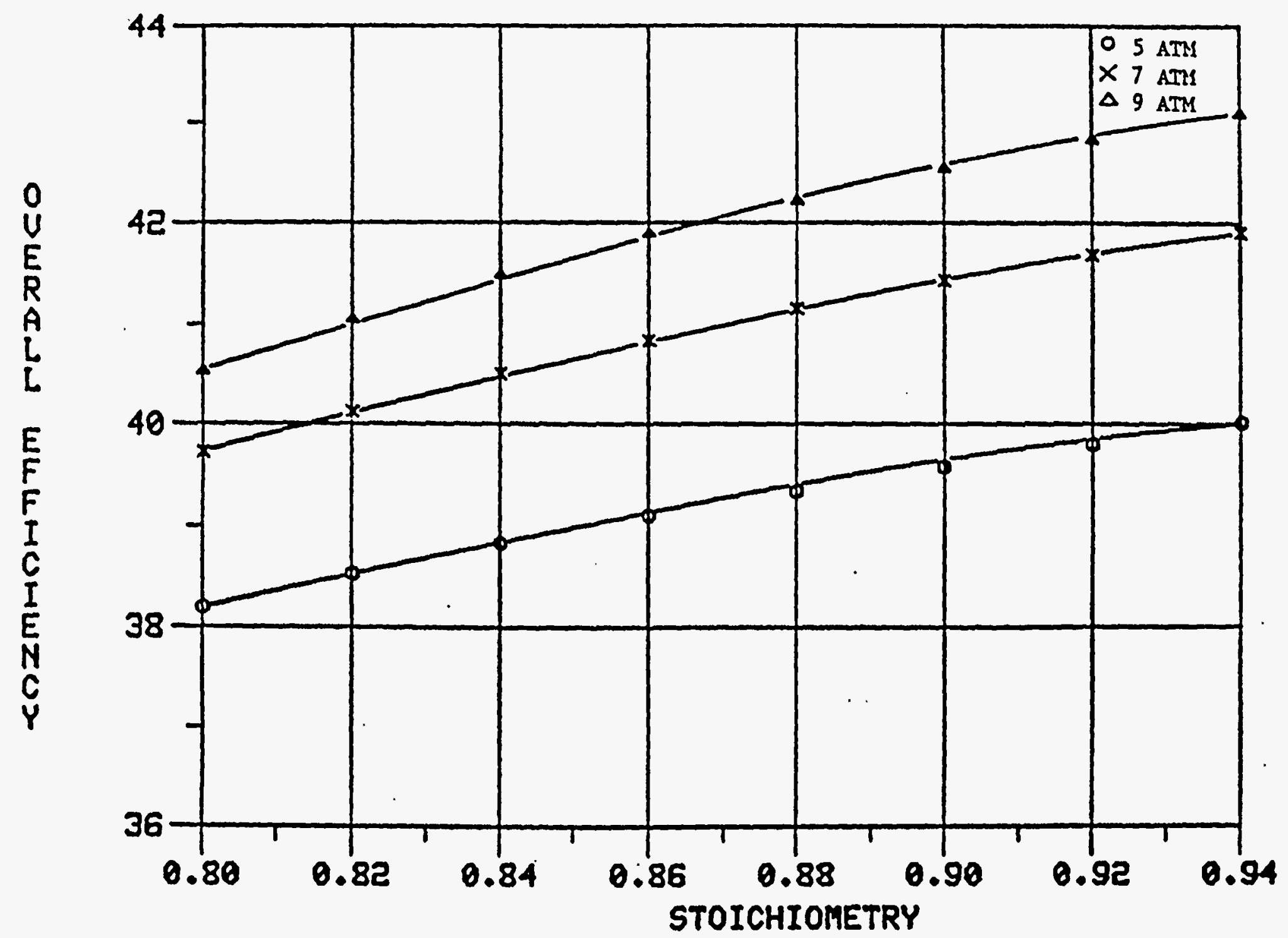

.Figure 1.2-6 Overall Efficiency vs. Primary Stoichiometry 368 Oxygen Enrichment by Volume (1000 MWe) 


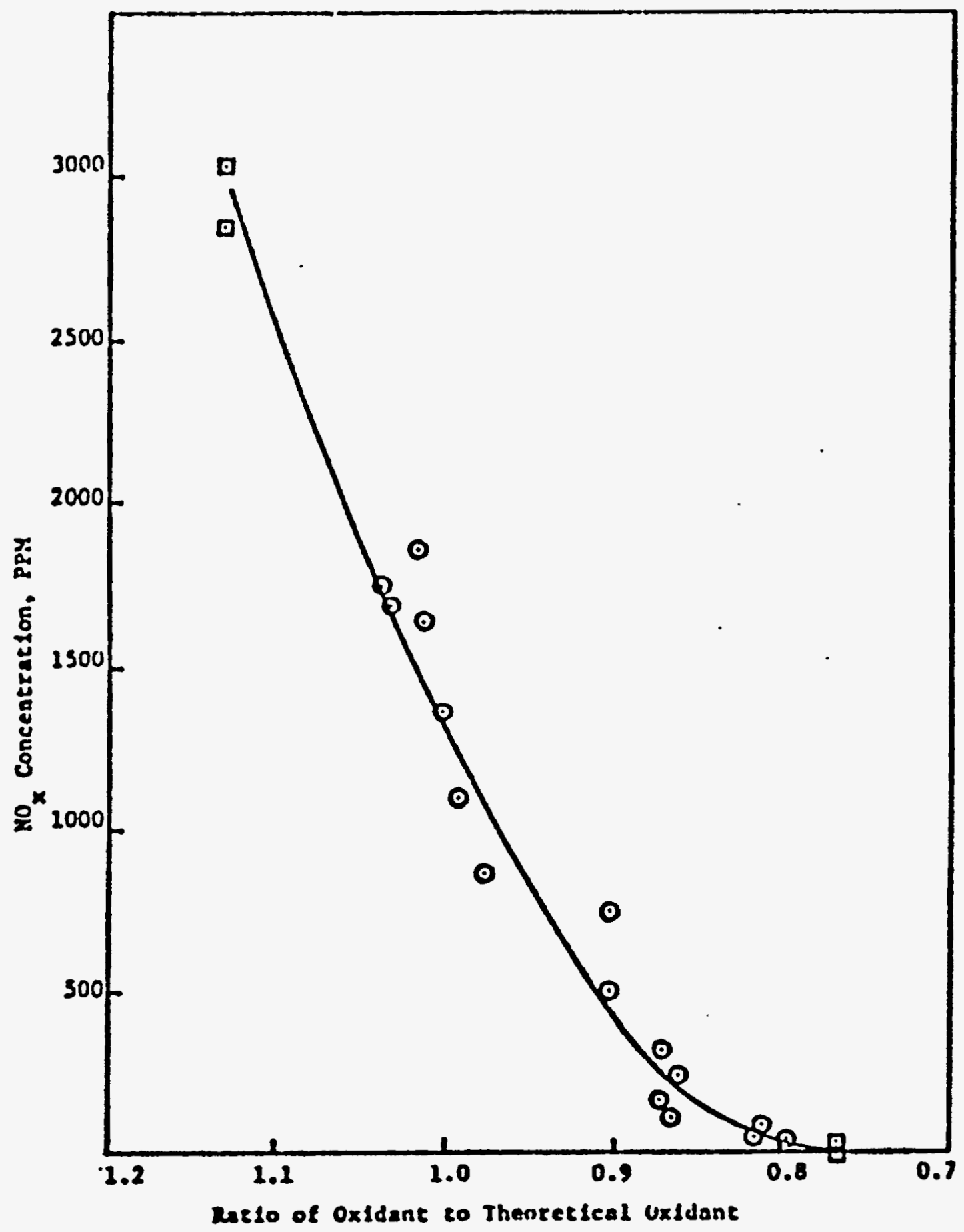

Figure 1.2-7 $\mathrm{NO}_{\mathrm{x}}$ at Cyclone Exit vis. Oxidänt Ratio 


\section{CHAPTER 2}

\section{THENOXEXPERIMENTS}

\subsection{The Experimental Apparatus}

\subsection{The Low Mass Flow (LMF) Train}

The LMF flow train was originally conceived and proposed as a simulation of the Coal Fired MHD Steam Power Plant concept. The Low Mass Flow designation was to distinguish the size at a nominal $20 \mathrm{MW}$ as opposed to the planned High Mass Flow (HMF) train which was to be at a nominal $50 \mathrm{MW}$ thermal input. The LMF test train was installed in Bay 1 and the HMF train was to be in Bay 2 of the CFFF test building. The HMF was never built at the CFFF although the superconducting magnet was completed and remains in storage at Argonne National Laboratory. In addition, the primary emphasis for the CFFF test program was shifted to the steam bottoming plant development in 1982 when the MHD development program was reduced in size.

The LMF flow train was fabricated and erected in stages as indicated in Table 2.1-1. The design philosophy for $\mathrm{NO}_{x}$ control was to burn sub-stoichiometrically in the primary combustor and design the radiant furnace to have sufficient heat transfer to cool the gas and sufficient residence time for the NO to decompose to near equilibrium at the reduced temperature.

TABLE 2.1-1

CFFF LMF TEST TRAIN CONFIGURATIONS

Iest Configurations

\begin{tabular}{|c|c|c|c|c|c|c|}
\hline COMPONENT & LMFO & LMF1 & LMF2 & LMF3 & LMF4 & LMF5 \\
\hline Vitiation Heater & $\bar{x}$ & $\bar{x}$ & $\bar{X}$ & $\bar{x}$ & $\bar{x}$ & $\bar{x}$ \\
\hline Coal Combustor & $\bar{x}$ & $\bar{x}$ & $\bar{x}$ & $\bar{x}$ & $\bar{x}$ & $\bar{x}$ \\
\hline Nozzle & $\bar{x}$ & $x$ & $x$ & $x$ & $\underline{x}$ & $\bar{x}$ \\
\hline MHD Generator & - & - & $\bar{x}$ & - & $\bar{x}$ & - \\
\hline Diagnostic Channel* & - & $\bar{x}$ & - & - & - & - \\
\hline Replacement Channel* & $\bar{x}$ & $\bar{x}$ & $x$ & $\bar{x}$ & $\bar{x}$ & $\bar{x}$ \\
\hline Diffuser & $\bar{x}$ & $\bar{x}$ & $\bar{x}$ & $\bar{x}$ & $\bar{x}$ & $\bar{x}$ \\
\hline Radiant Slagging Furnace & $x$ & $x$ & $\bar{x}$ & $\bar{x}$ & $x$ & $\bar{x}$ \\
\hline Secondary Combustor & $\bar{x}$ & $x$ & $\bar{x}$ & $\bar{x}$ & $\bar{x}$ & $\bar{x}$ \\
\hline $\begin{array}{l}\text { ITAH Materials Test } \\
\text { Module }\end{array}$ & - & $x$ & - & - & -- & - \\
\hline Superheater Test Module & - & - & $x$ & $\bar{x}$ & $\bar{x}$ & $\bar{x}$ \\
\hline Dry ESP & -- & - & - & -- & $\bar{x}$ & $\bar{x}$ \\
\hline Wet ESP & - & - & - & - & - & $\bar{x}$ \\
\hline Baghouse & - & - & - & $\bar{x}$ & $\bar{x}$ & $\bar{x}$ \\
\hline
\end{tabular}

"MHD Generator, Diagnostic Channel and Aerodynamic Replacement duct were used interchangeably. 


\subsection{Measurement Methodology}

$\mathrm{NO}_{x}$ measurements were made by inserting a probe into the gas stream and inducting a sample. The probe must be water cooled in most locations due to the high gas temperature. The extracted sample is cooled by the water cooled probe to quench the chemical reactions. It is then filtered to remove particulate from the sample. Next the gases enter a sample conditioner which provides additional particulate removal, acid gas removal and a dryer to remove water vapor. The sample is then applied to a commercial $\mathrm{NO}_{\mathrm{NO}} \mathrm{x}$ meter such as a Thermo Electron Model 10AR. The equipment to extract and process the sample was improved with experience over time as the testing progressed and modified for the specific location to optimize its performance. Detailed descriptions of this equipment and its operation are contained in Reference 6-7.

\section{3 $\quad \mathrm{NO}_{\mathrm{x}}$ Sampling Locations}

\subsubsection{The LMFO Test}

LMFO sampling locations are shown on Figure 2.3.1-16. The sample locations as shown on the Figure are T225:Radiant Furnace, T273:Secondary Combustor Inlet, T315:Secondary Combustor Outlet and the Stack. Typical results from these early tests are shown in Figures 2.3.1-2 and 2.3.1-3. Note that these results confirm that lower stoichiometry produces lower $\mathrm{NO}_{x}$ levels both at the radiant furnace and at the stack. The lower $\mathrm{NO}_{x}$ with $\mathrm{N} / \mathrm{O}$ ratio and with increased mass flow are indicative of the fact that higher temperatures produce more NO decomposition, even at the radiant furnace sampling location. These early tests were conducted with a slag screen in the radiant furnace, installed so that the diffuser exhaust impinged on it and flowed down past the slag screen, then back up in the radiant furnace. The result of this circuitous route through the lower furnace was a large temperature drop and a large decay in the NO concentration in the gas. (This effect led the DOE on-site representative to describe the slag screen as a "NOx disintegrator" during these early tests). Note, however, in Figure 2.3.13 that the stack $\mathrm{NO}_{x}$ values are high due to this rapid cooling in the lower radiant furnace plus the water quench immediately following the secondary combustor.

\subsubsection{LMF1 Tests}

The LMF1-A\&C sampling locations are shown in Figure 2.3.2-1.7 This test series had as a major objective the characterization of $\mathrm{NO}_{x}$ emissions. A total of eight $\mathrm{NO}_{x}$ sampling locations were used for these tests, including a sample port in the diffuser outlet and in the lower radiant furnace.

During this test series, systematic variations were made in primary stoichiometry, nitrogen-to-oxygen ratio and thermal input. Only the stoichiometry presents a clear "cause and effect" relationship with $\mathrm{NO}_{x}$ and even that also has some impact on gas temperature. A scatter plot showing much of the test data from the stack port versus stoichiometry as shown in Figure 2.3.2-2 perhaps best illustrates the relationship. Table 2.3.2-1 gives representative $\mathrm{NO}_{x}$ test data for each of the sample ports for the various conditions cited. Figure 2.3.2-3 shows this data for the radiant furnace inlet and the secondary combustor outlet for a number of different conditions. From this plot, one can see clearly the more rapid decomposition of NO in the fuel rich zone with lower stoichiometry. 


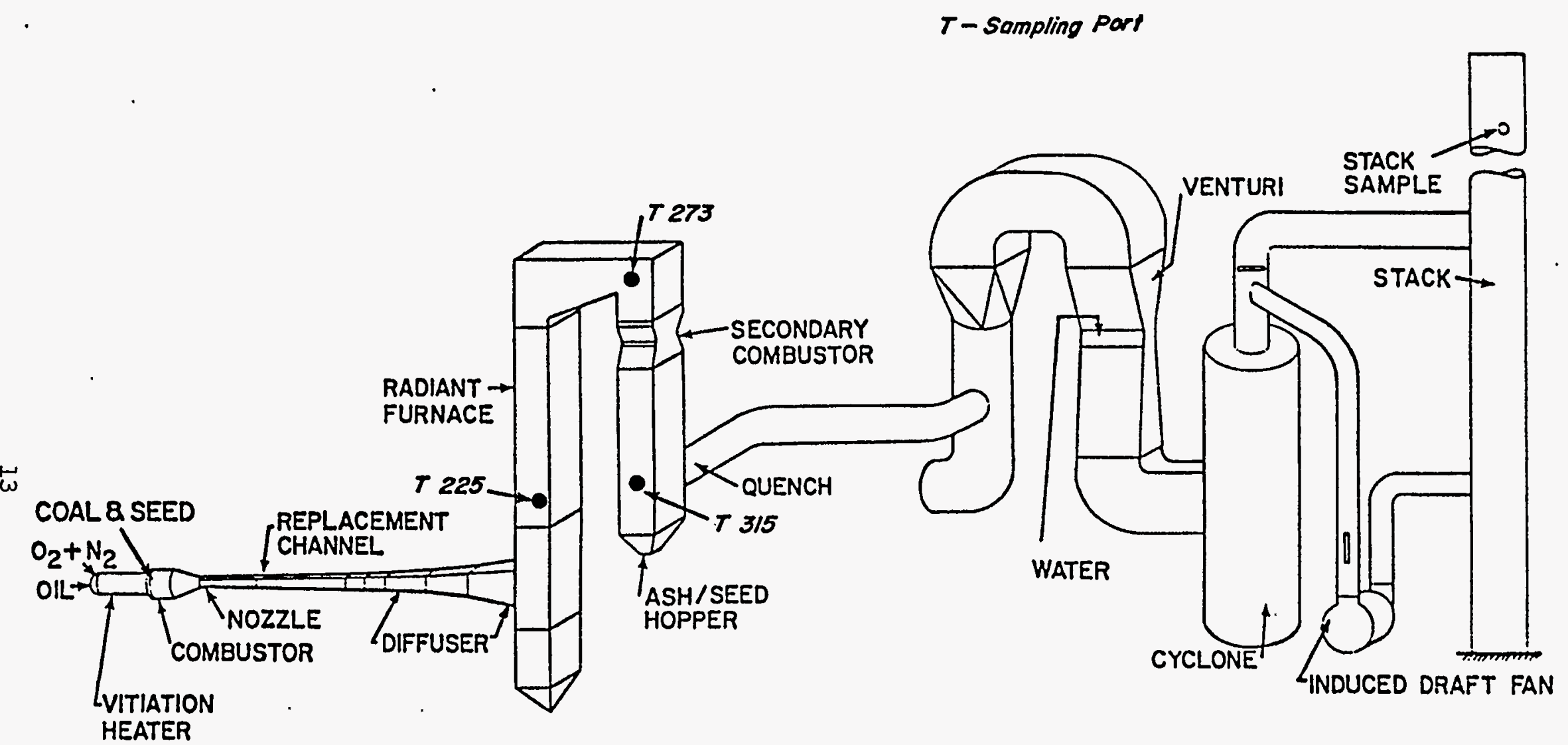

LMF-O TEST TRAIN CONFIGURATION

Figure 2.3.1-1 


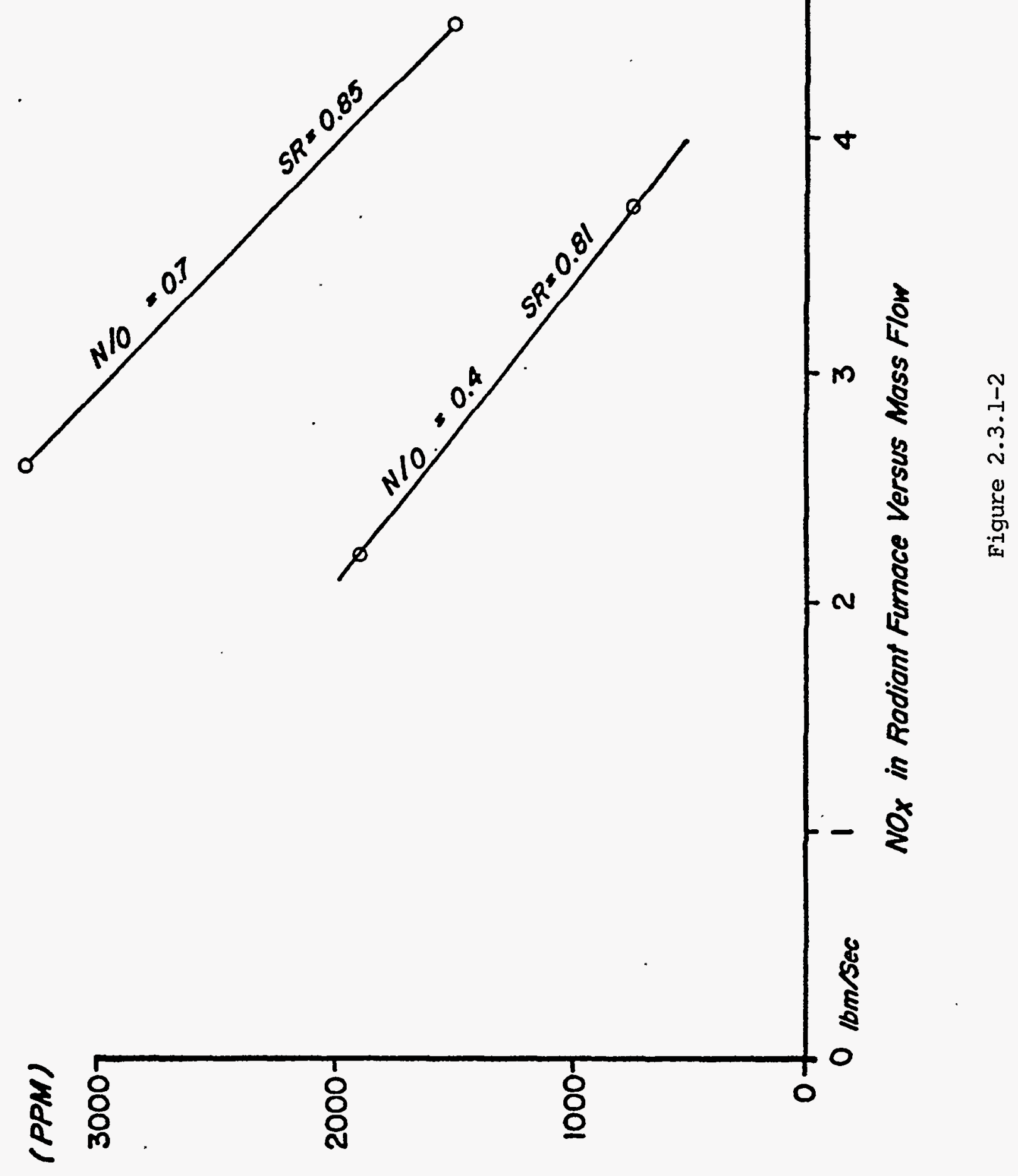




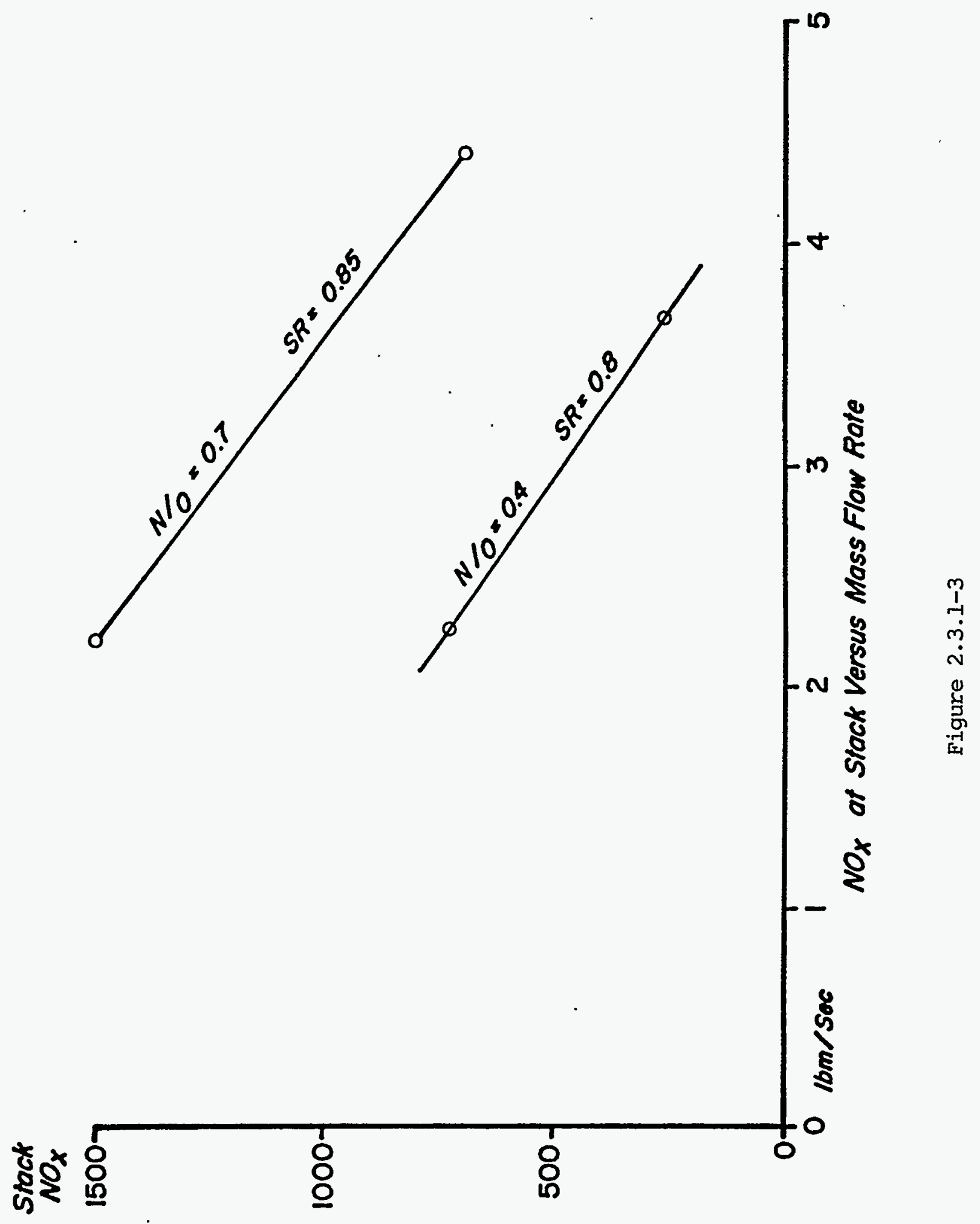




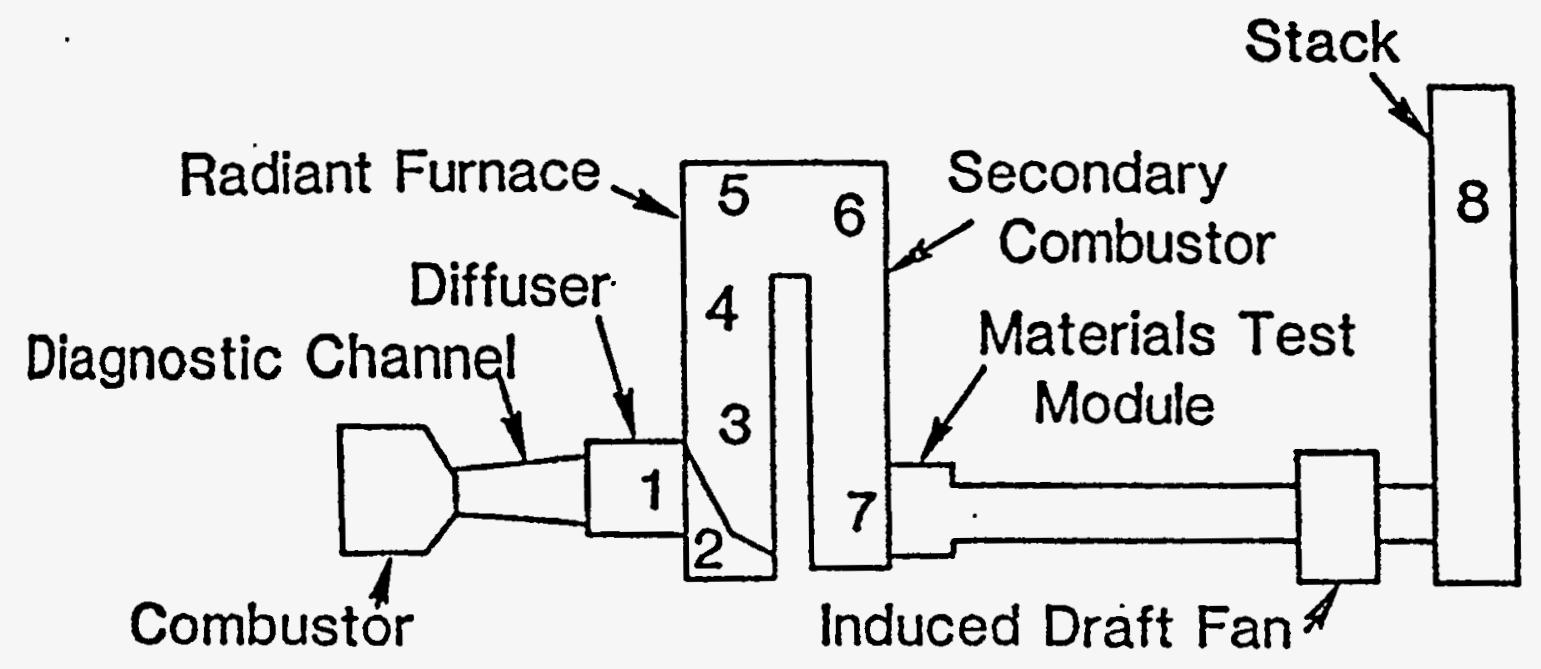

\begin{tabular}{|c|c|c|c|c|c|c|c|c|}
\hline \multirow{2}{*}{ Measurement } & \multicolumn{8}{|c|}{ Location / Nomenclature } \\
\hline & 1/DF5 & 2/RFO & 3/RF1 & 4/RF2 & 5/RF3 & $6 / 5 \mathrm{Cl}$ & $7 / 5 C 0$ & 8/STK \\
\hline NO / NOX & $x$ & $x$ & $x$ & $x$ & $x$ & $x$ & $x$ & $x$ \\
\hline $\mathrm{CO}$ & & & $x$ & & & $x$ & $x$ & $x$ \\
\hline $\mathrm{CO}_{2}$ & & & & & & & $x$ & $x$ \\
\hline$O_{2}$ & & & & & & & $x$ & $\mathbf{x}$ \\
\hline $\mathrm{SO}_{2}$ & & & & & & & $x$. & $x$ \\
\hline $\mathrm{GC} *$ & & & $x$ & & & & & \\
\hline
\end{tabular}

* At the end of the test series, the Gas Chromatograph wạs set up to measure $\mathrm{H}_{2}, \mathrm{CO}, \mathrm{C}_{2}$, $\mathrm{CH}_{4}, \mathrm{O}_{2}$, and $\mathrm{N}_{2} ; \mathrm{CO}$ and $\mathrm{CH}_{4}$ were not measured in early test8. 


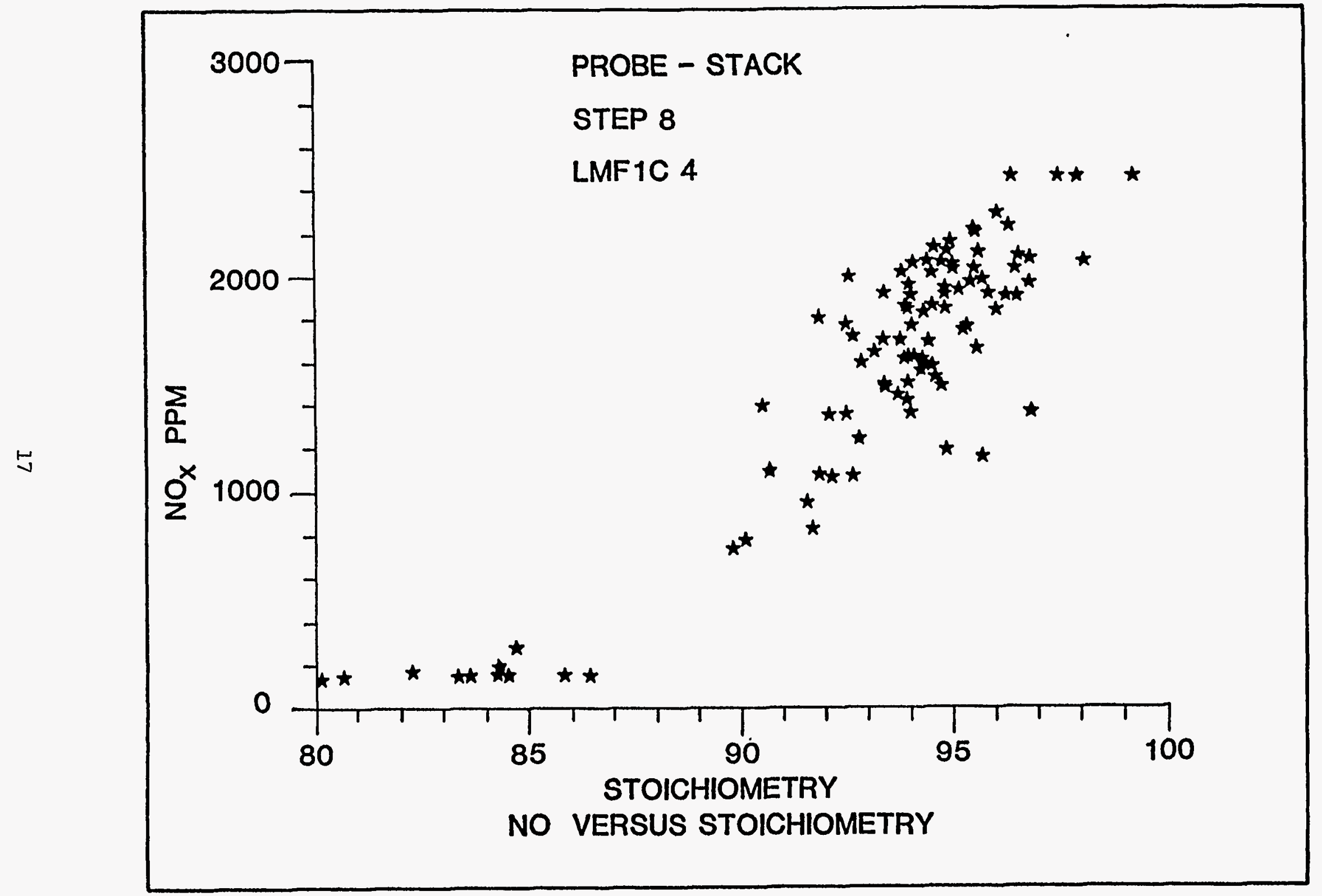

Figure 2.3.2-2 
TABLE 2.3.2-1

\section{$\phi$} च GAS ANALYSIS - LMF 1-C TESTS

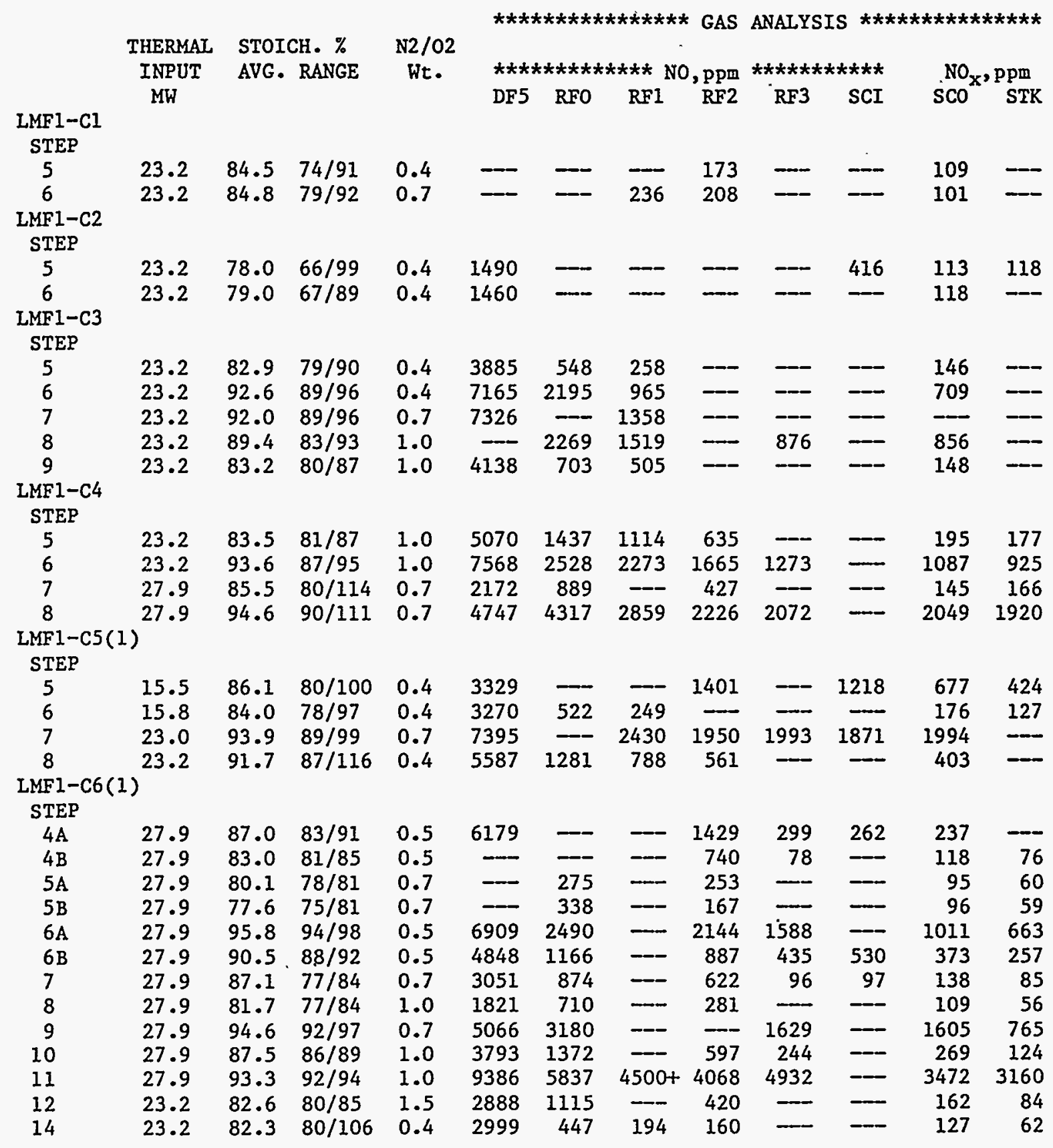

(1) STACK NO $x$ VALUES LOW DUE TO AIR LEAK. 


\section{CFFF TEST LMF 1C}

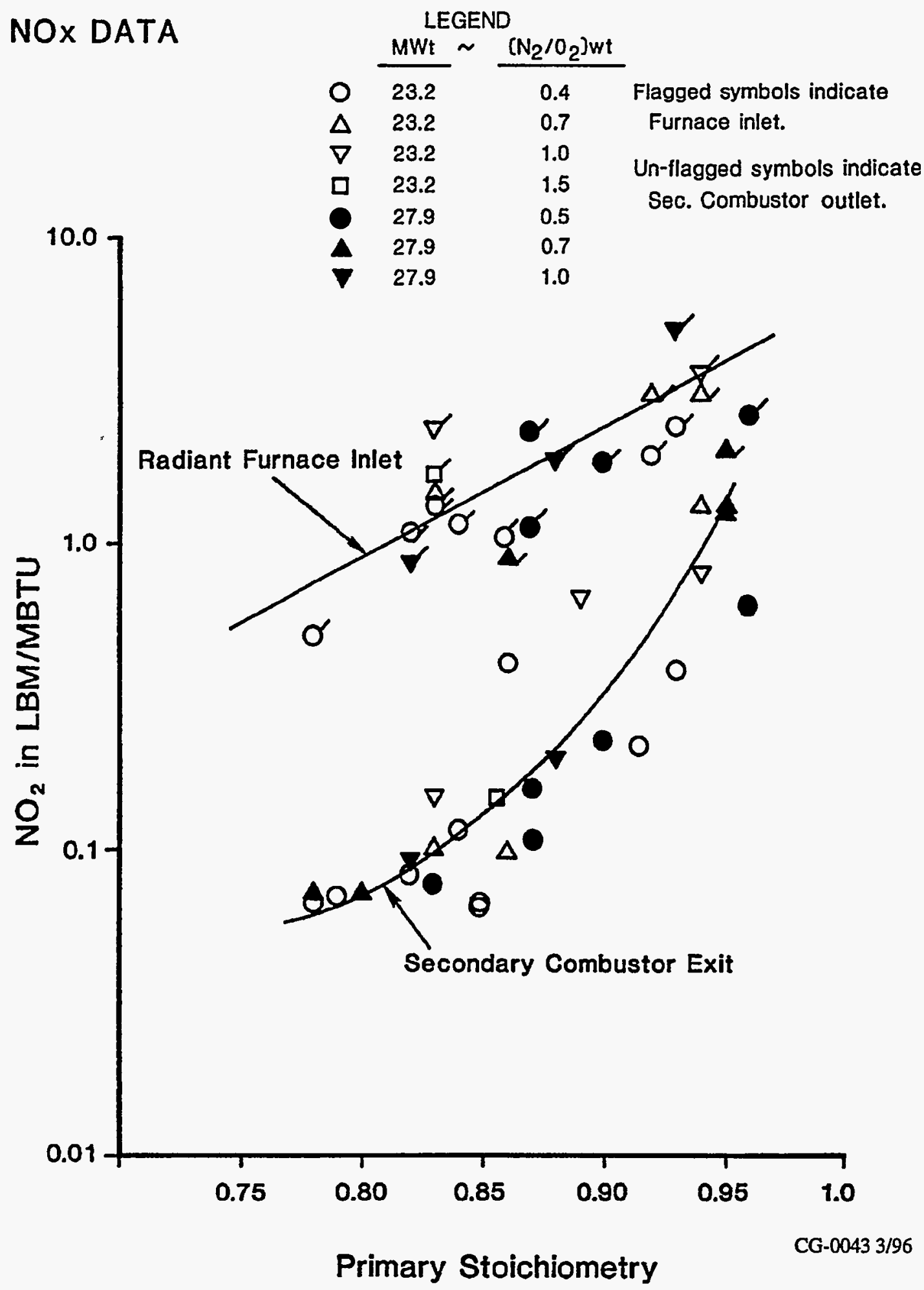

Figure 3.2-3 $\quad \mathrm{NO}_{2}$ and $\mathrm{N}_{2} \mathrm{O}$ (Equivalent) Levels at Radiant Furnace Inlet and Secondary Combustor Outlet Probes vs. Primary Stoichiometry. 
Because it is not feasible to change the furnace size and heat transfer characteristics to simulate everything about a commercial size plant, it was rapidly concluded that the value of this test series lies primarily in calibrating a computational model for $\mathrm{NO}_{x}$ decomposition.

The variables that affect $\mathrm{NO}_{x}$ control are the fuel, oxidant, gas temperature (especially that entering the radiant furnace), gas cooling rate in the furnace, temperature at which secondary combustion is completed, primary stoichiometry and the secondary combustion stoichiometry (overall stoichiometry). These issues are treated by use of the validated chemical kinetic model as described in the next section on modeling.

The probe used in the LMF diffuser was subject to high heat flux conditions. It was installed in a gas at high velocity and at temperatures in the $2200-2400 \mathrm{~K}\left(3500^{\circ} \mathrm{F}\right.$ to $3860^{\circ} \mathrm{F}$ ) range. As a result, some burnouts occurred during testing. In later tests, this measurement was normally not made because it jeopardized the reliability of tests with other primary objectives. It was also learned that within this high temperature range and at stoichiometries around $85 \%$, the final $\mathrm{NO}_{x}$ emission was almost independent of the diffuser $\mathrm{NO}_{x}$ level. This is not true, of course, for lower temperatures or higher stoichiometries.

Another problem experienced with extractive gas sampling in the high temperature zones was continued chemical reaction in the probe. That is, it was not possible to cool the gas rapidly enough to freeze the NO decomposition immediately upon the gas entering the probe for very high temperatures. A study8 of this effect showed that readings from the diffuser may be low by as much as $30 \%$ due to this effect.

\subsubsection{LMF2 \& 4 Tests}

The LMF2 test was conducted as a special configuration (including the $45^{\circ} \mathrm{DCW}$ MHD generator and the 3.2 Tesla magnet) of the LMF4 test series. The LMF3 test series was the first configuration that included the Superheater Test Module (SHTM). Components past the secondary combustor had little effect on the $\mathrm{NO}_{x}$ emissions so this and the later LMF4 series was largely a repeat of LMF1 tests insofar as $\mathrm{NO}_{\mathrm{x}}$ emissions are concerned. The variations in primary stoichiometry, thermal input and N/O were repeated for all configurations, however. The $\mathrm{NO}_{x}$ sampling ports for LMF3 are shown in Figure 2.3.3-1 and for early LMF4 in Figure 2.3.3-2. Later LMF4 tests used a redesigned SHTM, but there was negligible effects on $\mathrm{NO}_{x}$ emissions.

\subsubsection{LMF5 Tests}

The LMF5 tests included $\mathrm{NO}_{x}$ sampling ports identical to the later LMF4, but the fuel used was Montana Rosebud Coal. There were two major impacts on the $\mathrm{NO}_{x}$ emission levels, however. One relevant difference was that there was more heat loss to the walls in the upstream portion of the test train (combustor, nozzle, aerodynamic replacement duct and diffuser), which led to about $100 \mathrm{~K}\left(180^{\circ} \mathrm{F}\right)$ lower temperatures entering the radiant furnace. This difference in heat loss was attributed to the lower viscosity of the slag in the Western coal, thus a thinner slag layer on the walls. The other significant difference is that the Western coal has a sulfur content around $1 \%$ whereas the Eastern Coal (Illinois No. 6 Seam) typically had around $3 \%$ sulfur. This is due to the reactions for decomposition of NO that utilize sulfur. This is 


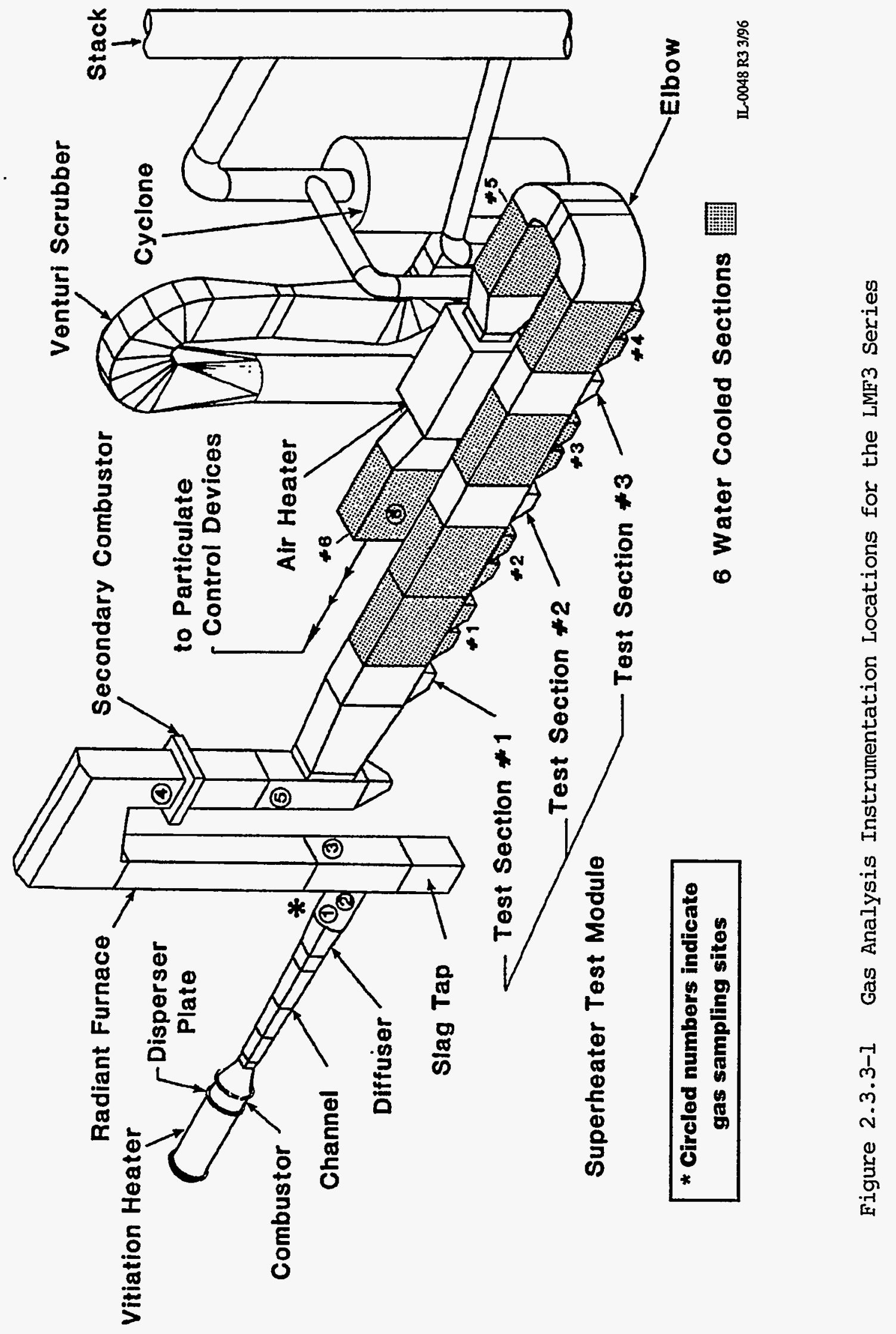




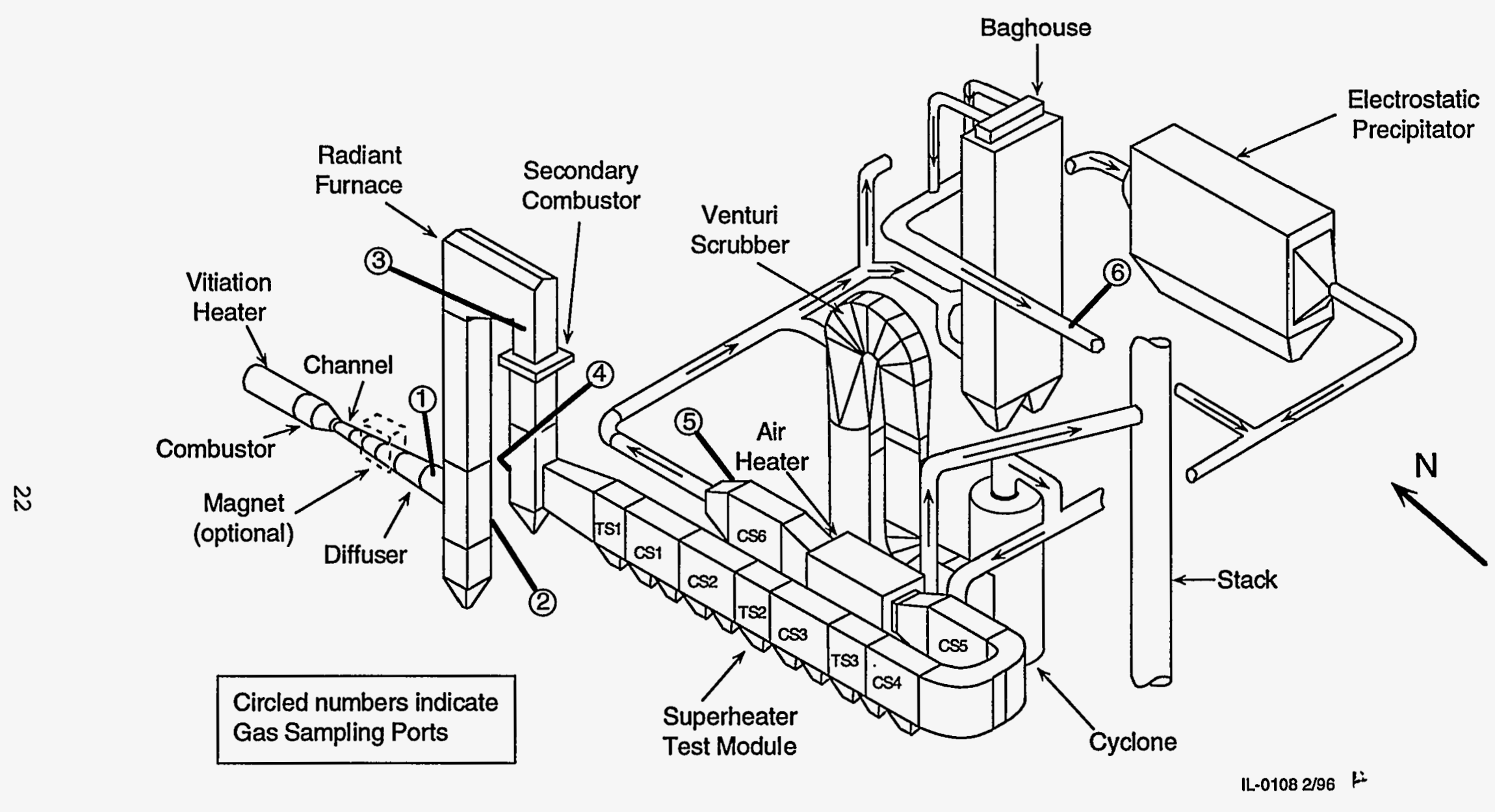

\section{LMF4 Test Train Configuration}

Figure 2.3.3-2 LMF4 Test Train Configuration 
discussed more fully in Chapter 3, Modeling. Figure 2.3.4-1 provides an aggregate view of the difference between Western and Eastern coal NO $\mathrm{N}_{\mathrm{x}}$ emissions. Note that in the LMF5-B test, sulfur was added to the Western coal and the $\mathrm{NO}_{\mathrm{x}}$ emissions were similar to that of the high sulfur Eastern coal. 


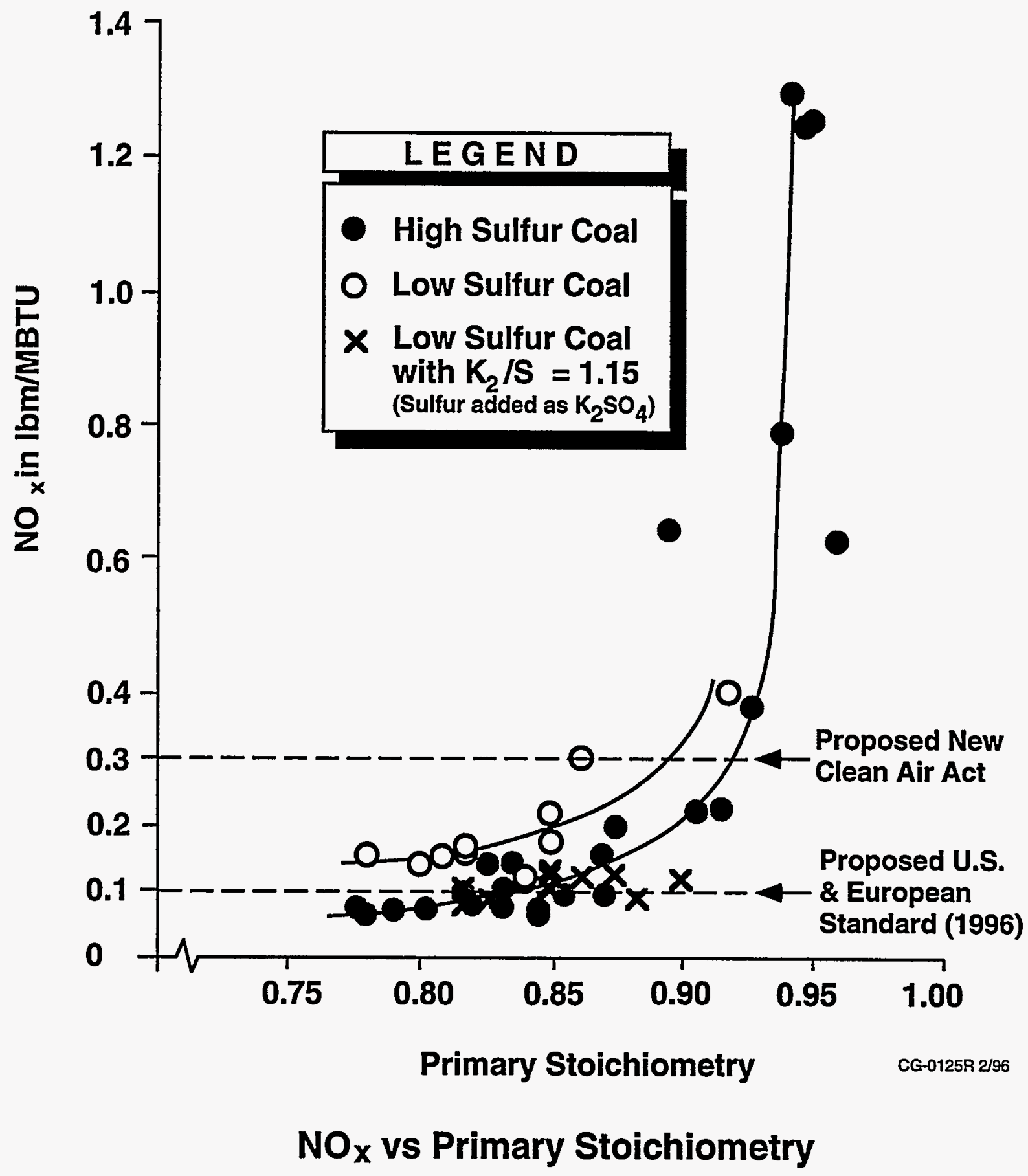

Figure 2.3.4-1 CFFF $\mathrm{NO}_{\mathrm{x}}$ Data 


\section{CHAPTER 3}

\section{NUMERICAL MODELING OF NITROGEN OXIDE DECOMPOSITION}

Chemical kinetic calculations have been carried out on the homogeneous reactions occurring in the radiant furnace. The calculations are performed from the CFFF diffuser exit through the upward pass of the radiant furnace into the secondary combustor. The computer program used has been adapted (most modifications involving input-output operations) from the "Premixed One-Dimensional Flame" (PROF) code developed for EPA.11 in the chemical kinetics calculations for the radiant furnace, the particular PROF option used has been that involving specification of an inlet composition together with temperature and pressure as a function of time. The time-temperature-pressure data are obtained from a furnace heat transfer calculation.

The numerical code requires a list of species with inlet concentrations, and a reaction set. For conditions which do not include sulfur, a total of 63 reactions are used involving 22 species containing the elements $\mathrm{C}, \mathrm{H}, \mathrm{N}$, and $\mathrm{O} .12$ For mixtures including sulfur, an additional 31 reactions involving some of the above 22 species and 8 more species containing $\mathrm{H}, \mathrm{N}, \mathrm{O}$, and $S$ are included.

Many reactions involving the $\mathrm{C}-\mathrm{H}-\mathrm{N}-\mathrm{O}$ species were obtained from a compilation presented by Hahn and Wendt 13 which was derived from a set described by Levy et al.14 in particular, the set presented in ref. 12 was decreased by excluding all $\mathrm{C}-\mathrm{H}$ and $\mathrm{C}-\mathrm{H}-0$ compounds, leaving 49 reactions. Reactions involving the formyl radical, $\mathrm{CHO}$, were obtained from Levy et al.15 which cites a pending publication by Corley and Bowman.16 Eight other reactions were included. The recommended list is in Table 3.1. Twenty-three of the reactions involving sulfur species were obtained from Wendt et al.17, four from other sources. The last four were postulated, using plausible parameters for the reaction rate coefficients.

The NO decomposition results for test LMF1C5, Step 5 (a low-stoichiometry oil run) were modeled using the set derived from Hahn and Wendt. ${ }^{3}$ (Species aside from NO were considered to be in equilibrium at the inlet, except that $\mathrm{H}_{2}, \mathrm{H}_{2} \mathrm{O}, \mathrm{CO}, \mathrm{CO}_{2}$, and $\mathrm{N}_{2}$, were adjusted to account for the measured inlet value of NO). It was found that the calculation led to too rapid a decomposition rate for NO, compared with experiment. One particular reaction, the reduction of HNO to $\mathrm{HN}$ by $\mathrm{CO}$, was found to lead to the over-prediction. On the other hand, complete exclusion of this particular reaction caused a very significant under-prediction of NO decomposition rate for the test in question. (Wendt et al.17 also found that this reaction overpredicted NO decomposition in a CO flame experiment, using the original estimated reaction rate coefficient). A number of alternatives were tested, but no other reaction was found which could cause the appropriate NO decomposition rate. For this reason, the reaction rate coefficient for the reaction $\mathrm{CO}+\mathrm{HNO} \geq \mathrm{CO}_{2}+\mathrm{HN}$ was adjusted to give the proper results for test LMF1C5, Step 5 , in conjunction with the remainder of the reaction set. In the adjustment, the activation energy was modified rather than the pre-exponential factor. It is important that the reaction set as a whole be considered, since, for example, modification of some of the other reaction rate coefficients, especially for other reactions involving $\mathrm{CO}$ being oxidized to $\mathrm{CO}_{2}$, and formation of HNO, could lead to a poor prediction for NO decomposition using the adjusted activation energy mentioned above.

$\mathrm{HN}$ may react with $\mathrm{NO}$ to form $\mathrm{N}_{2} \mathrm{O}$, which decomposes by a variety of paths to $\mathrm{N}_{2}$, or $\mathrm{HN}$ 
TABLE 3.1 KINETIC REACTION DATA

\begin{tabular}{|c|c|c|c|c|c|c|c|}
\hline \multicolumn{2}{|c|}{ REACTION } & \multirow[t]{2}{*}{ (a) } & & & Pre-exponential & \multirow{2}{*}{$\begin{array}{l}\text { Temp. } \\
\text { Exp. }\end{array}$} & \multirow{2}{*}{$\begin{array}{l}\text { Activiation } \\
\text { Energy, E (c) }\end{array}$} \\
\hline & & & & & Factor, A (b) & & \\
\hline $\mathrm{CO} 2$ & & $\mathrm{M}$ & $\mathrm{CO}$ & 0 & $.38000 E+31$ & -4 & 134.021 \\
\hline $\mathrm{CO}$ & $\mathrm{HO}$ & & $\mathrm{CO} 2$ & $\mathrm{H}$ & $.15000 \mathrm{E}+08$ & 1.3 & -.765 \\
\hline $\mathrm{CO}$ & 02 & & $\mathrm{CO} 2$ & 0 & $.32000 E+13$ & 0 . & 50. \\
\hline H2 & & $M$ & $\mathrm{H}$ & $\mathrm{H}$ & $.21000 \mathrm{E}+16$ & .07 & 103.83 \\
\hline HO & 0 & M & $\mathrm{HO} 2$ & & $.16000 \mathrm{E}+21$ & -1.5 & 0 . \\
\hline H & 02 & $\mathbf{M}$ & $\mathrm{HO} 2$ & & $.30000 E+16$ & 0 . & -1 \\
\hline $\mathrm{H} 2 \mathrm{O}$ & & $\mathbf{M}$ & HO & $\mathrm{H}$ & $.23000 \mathrm{E}+25$ & -2 & 122.6 \\
\hline $\mathrm{H}$ & HO & & $\mathrm{H} 2$ & 0 & $.27000 E+18$ & -.94 & 14.69 \\
\hline $\mathrm{H}$ & $\mathrm{HO} 2$ & & HO & HO & $.25000 \mathrm{E}+15$ & 0 & 1.9 \\
\hline HO & H2 & & $\mathrm{H}$ & $\mathrm{H} 2 \mathrm{O}$ & $.25000 E+14$ & 0 & 5.2 \\
\hline HO & HO & & $\mathrm{H} 2 \mathrm{O}$ & 0 & $.60000 E+13$ & 0 & 1. \\
\hline HO & 0 & & $\mathrm{H}$ & 02 & $.63000 \mathrm{E}+12$ & .5 & 0 \\
\hline $\mathrm{HO} 2$ & $\mathrm{H}$ & & 02 & $\mathrm{H} 2$ & $.25000 \mathrm{E}+14$ & 0 & .7 \\
\hline $\mathrm{HO} 2$ & 0 & & HO & 02 & $.50000 E+14$ & 0 & 1. \\
\hline $\mathrm{CHN}$ & HO & & $\mathrm{CN}$ & $\mathrm{H} 2 \mathrm{O}$ & $.20000 \mathrm{E}+12$ & .6 & 5. \\
\hline $\mathrm{CN}$ & $\mathrm{CO} 2$ & & $\mathrm{NCO}$ & $\mathrm{CO}$ & $.37000 E+13$ & 0 & 0. \\
\hline $\mathrm{CN}$ & HO & & NCO & $\mathrm{H}$ & $.62000 \mathrm{E}+14$ & 0 . & 0. \\
\hline $\mathrm{CN}$ & $\mathrm{H} 2$ & & $\mathrm{CHN}$ & $\mathrm{H}$ & $.62000 \mathrm{E}+13$ & 0. & 5.3 \\
\hline $\mathrm{CN}$ & 0 & & $\mathrm{CO}$ & $\mathrm{N}$ & $.63000 \mathrm{E}+12$ & .5 & 0 \\
\hline $\mathrm{NCO}$ & $\mathrm{H}$ & & HN & $\mathrm{CO}$ & $.50000 E+12$ & .5 & 6.87 \\
\hline $\mathrm{CO}$ & HNO & & $\mathrm{CO} 2$ & $\mathrm{HN}$ & $.10000 E+12$ & .5 & 21.0 \\
\hline $\mathrm{H}$ & NO & $\mathbf{M}$ & HNO & & $.20000 E+17$ & 0. & 0. \\
\hline No & 0 & $M$ & $\mathrm{NO} 2$ & & $.14000 \mathrm{E}+22$ & -1.82 & 0 \\
\hline $\mathrm{N} 2 \mathrm{O}$ & & $\mathbf{M}$ & N2 & 0 & $.40000 E+15$ & 0. & 51.4 \\
\hline $\mathrm{H}$ & HNO & & $\mathrm{H} 2$ & NO & $.10000 \mathrm{E}+14$ & 0. & 2.5 \\
\hline $\mathrm{H}$ & $\mathrm{N} 2 \mathrm{O}$ & & HO & $\mathrm{N} 2$ & $.80000 E+14$ & 0 . & 15 . \\
\hline HN & NO & & $\mathrm{H}$ & $\mathrm{N} 2 \mathrm{O}$ & $.90000 E+10$ & .75 & 00 \\
\hline $\mathrm{H}$ & NO2 & & HO & NO & $.32000 \mathrm{E}+15$ & 0 . & 1.5 \\
\hline HNO & HO & & $\mathrm{H} 2 \mathrm{O}$ & NO & $.36000 \mathrm{E}+14$ & 0 . & 0 . \\
\hline HNO & 0 & & $\mathrm{HO}$ & NO & $.50000 \mathrm{E}+12$ & .5 & 0 \\
\hline HNO & 0 & & $\mathrm{HN}$ & 02 & $.10000 \mathrm{E}+12$ & .5 & 7. \\
\hline HO & $\mathrm{N} 2 \mathrm{O}$ & & $\mathrm{HO} 2$ & N2 & $.32000 E+14$ & 0. & 15 . \\
\hline N2 & $\mathrm{O}$ & & No & $\mathrm{N}$ & $1.84+14$ & 0 & 76.25 \\
\hline 0 & No & & $\mathbf{N}$ & $\mathrm{O} 2$ & $2.36+09$ & 1.0 & 38.65 \\
\hline NO & $\mathrm{H}$ & & $\mathrm{N}$ & $\mathrm{HO}$ & $2.22+14$ & 0 & 50.5 \\
\hline HN & $\mathrm{H}$ & & $\mathbf{N}$ & $\mathrm{H} 2$ & $.63000 \mathrm{E}+12$ & .5 & 8. \\
\hline $\mathrm{HN}$ & HO & & $\mathrm{H} 2 \mathrm{O}$ & $\mathrm{N}$ & $.50000 \mathrm{E}+12$ & .5 & 2 . \\
\hline $\mathrm{HN}$ & HO & & No & $\mathrm{H} 2$ & $.50000 \mathrm{E}+12$ & .5 & 2 . \\
\hline HN & 0 & & No & $\mathrm{H}$ & $.63000 E+12$ & .5 & 0 \\
\hline $\mathrm{H} 2 \mathrm{~N}$ & $\mathrm{H}$ & & $\mathrm{HN}$ & $\mathrm{H} 2$ & $.14000 \mathrm{E}+12$ & .67 & 4.3 \\
\hline $\mathrm{H} 2 \mathrm{~N}$ & HO & & HN & $\mathrm{H} 2 \mathrm{O}$ & $.30000 E+11$ & .68 & 1.3 \\
\hline $\mathrm{H} 2 \mathrm{~N}$ & 0 & & $\mathrm{HN}$ & HO & $.92000 \mathrm{E}+12$ & .5 & 0. \\
\hline $\mathrm{H} 2 \mathrm{~N}$ & $\mathrm{H} 2 \mathrm{~N}$ & & $\mathrm{H} 3 \mathrm{~N}$ & HN & $.17000 \mathrm{E}+12$ & .63 & 3.6 \\
\hline $\mathrm{H} 3 \mathrm{~N}$ & HO & & $\mathrm{H} 2 \mathrm{~N}$ & $\mathrm{H} 2 \mathrm{O}$ & $.17600 \mathrm{E}+13$ & 0 . & 1.7 \\
\hline $\mathrm{H} 3 \mathrm{~N}$ & $\mathrm{H}$ & & $\mathrm{H} 2 \mathrm{~N}$ & $\mathrm{H} 2$ & $.24600 \mathrm{E}+14$ & 0 . & 17.07 \\
\hline $\mathrm{H} 2 \mathrm{~N}$ & NO & & N2 & $\mathrm{H} 2 \mathrm{O}$ & $.50000 \mathrm{E}+13$ & 0 . & 0. \\
\hline $\mathrm{H} 3 \mathrm{~N}$ & 0 & & $\mathrm{H} 2 \mathrm{~N}$ & HO & $.15000 \mathrm{E}+13$ & 0 & 6. \\
\hline H3N & $\mathrm{O} 2$ & & $\mathrm{H} 2 \mathrm{~N}$ & $\mathrm{HO} 2$ & $.50000 \mathrm{E}+12$ & .5 & 56. \\
\hline No & $\mathrm{HO}_{2}$ & & $\mathrm{NO} 2$ & HO & $.50000 \mathrm{E}+12$ & .5 & 3.52 \\
\hline
\end{tabular}


Table 3.1 Kinetic Reaction Data Continued

\begin{tabular}{|c|c|c|c|c|c|c|c|}
\hline $\mathrm{HN}$ & HO & & HNO & $\mathrm{H}$ & $5.00+11$ & .5 & 5.62 \\
\hline $\mathrm{CO}$ & $\mathrm{N} 2 \mathrm{O}$ & & $\mathrm{CO} 2$ & N2 & $3.00+11$ & 0. & 17.2 \\
\hline $\mathrm{CHO}$ & & $\mathbf{M}$ & $\mathrm{H}$ & $\mathrm{CO}$ & $1.55 \mathrm{E}+14$ & 0 & 14.7 \\
\hline $\mathrm{CHO}$ & $\mathrm{H}$ & & $\mathrm{CO}$ & $\mathrm{H} 2$ & $2.00 E+14$ & 0 & 0 \\
\hline $\mathrm{CHO}$ & $\mathrm{O}$ & & $\mathrm{CO}$ & $\mathrm{HO}$ & $5.50 \mathrm{E}+12$ & 0.5 & 0 \\
\hline $\mathrm{CHO}$ & 0 & & $\mathrm{CO} 2$ & $\mathrm{H}$ & $5.50 E+12$ & 0.5 & 0 . \\
\hline $\mathrm{CHO}$ & HO & & $\mathrm{CO}$ & $\mathrm{H} 2 \mathrm{O}$ & $3.00 \mathrm{E}+12$ & 1.0 & 0 \\
\hline $\mathrm{CHO}$ & $\mathrm{O} 2$ & & $\mathrm{CO}$ & $\mathrm{HO} 2$ & $5.00 \mathrm{E}+11$ & 0.5 & 0.83 \\
\hline $\mathrm{H} 2 \mathrm{~N}$ & 0 & & $\mathrm{H}$ & HNO & $2.10 \mathrm{E}+12$ & 0.0 & 0.00 \\
\hline $\mathrm{CO} 2$ & $\mathrm{~N}$ & & NO & $\mathrm{CO}$ & $2.00 \mathrm{E}+11$ & -.5 & 8.00 \\
\hline NO & NO & & $\mathrm{N} 2 \mathrm{O}$ & 0 & 1. $29 \mathrm{E}+12$ & 0.0 & 63.8 \\
\hline HNO & HNO & & $\mathrm{N} 2 \mathrm{O}$ & $\mathrm{H} 2 \mathrm{O}$ & $.300 \mathrm{E}+12$ & 0.0 & 3.5 \\
\hline NO & HNO & & $\mathrm{N} 20$ & HO & $2.00 \mathrm{E}+12$ & 0.0 & 26 . \\
\hline NO & NO & & N2 & 02 & $3.10 \mathrm{E}+13$ & 0.0 & 63.1 \\
\hline $\mathrm{K}$ & $\mathrm{H} 2 \mathrm{O}$ & & HKO & $\mathrm{H}$ & $6.02+13$ & 0 & 39.7 \\
\hline $\mathrm{K}$ & HO & M & HKO & & $2.18+20$ & -1 & 0 \\
\hline KO & HO & & HKO & 0 & $2.00+11$ & 0.5 & 8. \\
\hline KO & $\mathrm{H}$ & & $\mathrm{HO}$ & $\mathrm{K}$ & $2.00+11$ & 0.5 & 8. \\
\hline HS & $\mathbf{S}$ & & $\mathrm{H}$ & $\mathrm{S2}$ & $6.31+11$ & .5 & .000 \\
\hline HS & $\mathrm{H}$ & & $\mathbf{S}$ & $\mathrm{H} 2$ & $6.31+11$ & .5 & 0.000 \\
\hline $\mathrm{H} 2 \mathrm{~S}$ & $\mathrm{H}$ & & HS & $\mathrm{H} 2$ & $9.03+12$ & .0 & 1.700 \\
\hline HS & HS & & $\mathrm{H} 2 \mathrm{~S}$ & $\mathrm{~S}$ & $1.00+14$ & .0 & 1.420 \\
\hline HO & $\mathrm{H} 2 \mathrm{~S}$ & & $\mathrm{H} 2 \mathrm{O}$ & HS & $1.40+13$ & .0 & .894 \\
\hline os & Hо & & $\mathrm{H}$ & O2S & $6.46+14$ & .0 & 2.10 \\
\hline$s$ & HO & & OS & $\mathrm{H}$ & $6.31+11$ & .5 & .000 \\
\hline HS & 0 & & OS & $\mathrm{H}$ & $6.31+11$ & .5 & .000 \\
\hline 0 & $\mathrm{H} 2 \mathrm{~S}$ & & HS & HO & $4.40+12$ & .0 & 3.298 \\
\hline HS & 0 & & $S$ & HO & $6.31+11$ & .5 & 8.00 \\
\hline OS & 02 & & $02 S$ & 0 & $1.81+11$ & .0 & 5.600 \\
\hline $\mathbf{S}$ & 02 & & os & 0 & $6.31+11$ & .5 & 0 \\
\hline 0 & s2 & & OS & $S$ & $6.31+11$ & .5 & .0 \\
\hline os & os & & O2S & $S$ & $4.10+11$ & .0 & 3.23 \\
\hline $\mathbf{s}$ & $\mathrm{H} 2 \mathrm{O}$ & & HS & HO & $4.40+12$ & .0 & 28 \\
\hline $\mathbf{S}$ & $S$ & $M$ & S2 & & $1.00+18$ & -1 & 0 \\
\hline$s$ & 0 & M & os & & $5.50+13$ & .0 & 1.788 \\
\hline$S$ & $\mathrm{H}$ & M & HS & & $7.20+15$ & .0 & 0. \\
\hline $\mathrm{H} 2 \mathrm{~S}$ & & M & HS & $\mathrm{H}$ & $2.00+14$ & .0 & 74 \\
\hline OS & 0 & M & O2S & & $1.22+22$ & -1.84 & 0 \\
\hline $\mathrm{O} 2 \mathrm{~S}$ & 0 & M & O3S & & $4.00+20$ & -4 & 5.3 \\
\hline O3S & $\mathrm{O}$ & & O2S & $\mathrm{O} 2$ & $2.80+14$ & 0 & 12.0 \\
\hline $\mathrm{N}$ & os & & NO & $S$ & $6.31+11$ & .5 & 2. \\
\hline NO & $S$ & & NS & 0 & $1.00+12$ & .5 & 34.8 \\
\hline NS & 0 & & os & $\mathrm{N}$ & $6.31+11$ & .5 & 8. \\
\hline$N$ & NS & & N2 & $S$ & $6.31+11$ & .5 & 0 \\
\hline $\mathrm{N}$ & HS & & NS & $\mathrm{H}$ & $6.31+11$ & .5 & 8. \\
\hline OS & HNO & & $\mathrm{O} 2 \mathrm{~S}$ & HN & $6.31+1 I$ & .5 & 8. \\
\hline NO & NS & & $\mathrm{N} 2 \mathrm{O}$ & $S$ & $6.31+11$ & .5 & 8. \\
\hline $\mathrm{N}$ & O2S & & No & OS & $2.00+11$ & .5 & 8.0 \\
\hline $\mathrm{H} 2 \mathrm{~N}$ & HS & & H2S & $\mathrm{HN}$ & $6.31+11$ & .5 & 0.0 \\
\hline $\operatorname{cs} 2$ & 0 & & CS & OS & $.50000 E+14$ & 0 & 1.9 \\
\hline $\operatorname{cs} 2$ & 0 & & $\cos$ & $S$ & $.17000 E+13$ & 0 . & 1.2 \\
\hline
\end{tabular}


Table 3.1 Kinetic Reaction Data Continued

\begin{tabular}{|c|c|c|c|c|c|c|c|}
\hline $\operatorname{cs} 2$ & 0 & & $\mathrm{CO}$ & s2 & $.32000 E+13$ & 0. & 1.0 \\
\hline $\cos$ & 0 & & $\mathrm{CO}$ & os & $.60000 \mathrm{E}+14$ & 0 . & 5.5 \\
\hline $\cos$ & 0 & & $\mathrm{CO} 2$ & $s$ & $.12000 \mathrm{E}+15$ & 0 . & 11. \\
\hline CS & 0 & & $\mathrm{CO}$ & $\mathrm{s}$ & $.11000 \mathrm{E}+14$ & 0 . & 41. \\
\hline $\operatorname{cs} 2$ & $\mathrm{~s}$ & & CS & S2 & $.15000 E+14$ & 0 . & 00 . \\
\hline $\cos$ & $\mathbf{s}$ & & $\mathrm{CO}$ & s2 & $.90000 \mathrm{E}+12$ & 0 . & 2.5 \\
\hline $\cos$ & OS & & $\mathrm{CO} 2$ & s2 & $.10000 \mathrm{E}+09$ & 0 . & 0 . \\
\hline CS & 02 & & CO & os & $.55000 E+08$ & 0 . & 2 . \\
\hline CS & 02 & & $\cos$ & 0 & $.31000 \mathrm{E}+10$ & 0. & 9.5 \\
\hline CS & os & & CO & S2 & $.10000 \mathrm{E}+14$ & 0. & 00 . \\
\hline CS & $s$ & $M$ & Cs2 & & $.51000 \mathrm{E}+25$ & -3 & 00 . \\
\hline CO & $s$ & $\mathbf{M}$ & $\cos$ & & $.29000 E+26$ & -3.6 & 00. \\
\hline 0 & $\mathrm{KS}$ & & Ko & $s$ & $6.31+11$ & .5 & 8. \\
\hline KO & HS & & $\mathrm{KS}$ & HO & $6.31+11$ & .5 & 8. \\
\hline но & $\mathrm{KS}$ & & HKO & $s$ & $6.31+11$ & .5 & 8. \\
\hline $\mathrm{H}$ & $\mathrm{KS}$ & & $\mathrm{k}$ & HS & $6.31+11$ & .5 & 8. \\
\hline KO & NS & & KS & NO & $6.31+11$ & .5 & 8. \\
\hline $\mathrm{CO}$ & $\mathrm{KS}$ & & $\cos$ & $\mathrm{K}$ & $6.31+11$ & .5 & 8. \\
\hline
\end{tabular}

NOTES :

(a) Species $M$, any gaseous species, exchanges energy but does not react. $M$ also participates in the reverse direction.

(b) Units are Mole-cm-sec. Forward rate coefficient, in direction shown, is given in Arrhenius form $A *\left(T * *_{n}\right) * \exp (-E / R * T), T$ in $K$. Reverse rate coefficient is obtained from (forward coefficient)/ (concentration equilibrium constant).

(c) Units are KCAL/MOLE 
may accept an atom of $\mathrm{H}$ to form $\mathrm{H}_{2} \mathrm{~N}$, which can react with $\mathrm{NO}$ to form $\mathrm{N}_{2}$. It is important to note that ammonia, $\mathrm{NH}_{3}$, may form to a level of several ppm, but is not added in the tests conducted or calculations in this report.

The result of the calculations for test LMF1C5, Step 5 is shown in Figure 3-1 together with a result obtained omitting the reduction of $H N O$ to $H N$. It is evident that the conventional decomposition mechanism through $\mathbf{N}$ atoms (the modified Zeldovich mechanism) is inadequate to predict the NO decomposition.

As a particular example of NO decomposition involving coal as fuel, the result from CFFF test LMF1C4, Step 5 is illustrated in Figure 3-2. This was also a low stoichiometry test, with a somewhat higher mass flow and thermal input, hence a higher furnace inlet temperature, than the previous oil test analyzed. It is apparent from the calculated results that decomposition through the Zeldovich mechanism is greater in this case, but even with HN formation from HNO, the experimental NO decomposition rate is more rapid than the predicted rate. Incorporation of the reactions involving sulfur species significantly improves the agreement between numerical analysis and experiment.

Figure 3-3 shows NO decomposition for test LMF1C6, Step 9 (a test at higher stoichiometry than the above), together with calculated results (i) excluding sulfur reactions and $H N$ formation from HNO, (ii) including $H N$ formation, and (iii) including $H N$ formation and sulfur reactions. It is apparent from these results that the reverse Zeldovich mechanism accounts for most of the decomposition.

The question naturally arises as to whether, in the coal-fired tests, there could be some residual unburned carbon which could reduce NO heterogeneously. The retention time in the high-pressure combustor of the CFFF is relatively short, generally 50 milliseconds or less, depending on conditions. Some additional time for carbon burning, if required, is available in the diffuser before the combustion products enter the furnace. For at least two reasons, the effect of heterogeneous reduction of $\mathrm{NO}$ is thought to be minimal. First, examination of furnace deposits (post-test) in the CFFF tests has never shown any significant carbon content in deposits. The second reason is related to a completely independent research effort by Glass and Wendt. 18 In that study, a Utah bituminous coal was burned in a laboratory combustor with air at a stoichiometry of 0.8 . Careful measurements after the major part of combustion had occurred showed up to 10 percent unburned carbon at temperatures in the range 1600-1800K with a retention time of about 1 sec., time-temperature conditions similar to those in the CFFF radiant furnace. However, a heterogeneous mechanism, which, according to Glass and Wendt, yielded higher rates than any previously used, still failed to predict the observed decomposition rate of NO. Glass and Wendt observed decomposition of NO from $1000 \mathrm{ppmv}$ to $500 \mathrm{ppmv}$, while they predicted an exit value as a result of the heterogeneous reduction reaction, of $9000 \mathrm{ppmv}$. A crude approximation, assuming complete carbon combustion, yielded an exit value of about 600 ppmv, using the homogeneous reaction set in Table 3.1 .

A point which has not been addressed above is the question of how nitric oxide is formed in the CFFF, as opposed to how it decomposes. It is usually assumed that, at the high temperature and pressure of the primary combustor, NO will approach equilibrium in the gas phase very rapidly. Kalfadelis et al.19 carried out a numerical experiment which showed that, in the primary MHD combustor, NO would reach within 90 percent of the equilibrium value in $1 \mathrm{~ms}$ at $2830 \mathrm{~K}$, and in $2 \mathrm{~ms}$ at $2700 \mathrm{~K}$ for the conditions they chose. 


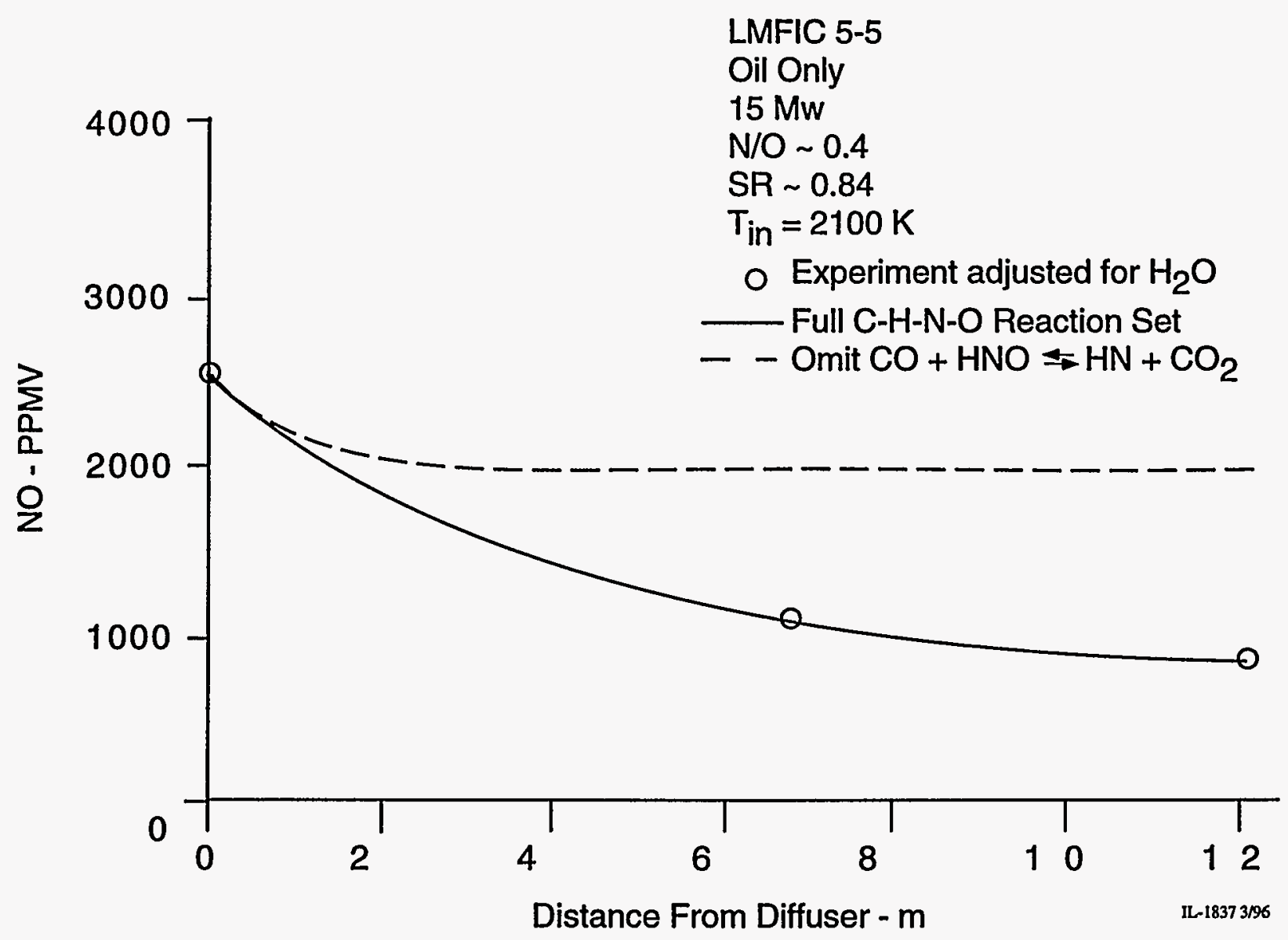

Figure 3.1 Calculated and Experimental NO Levels in CFFF Flow Train. 


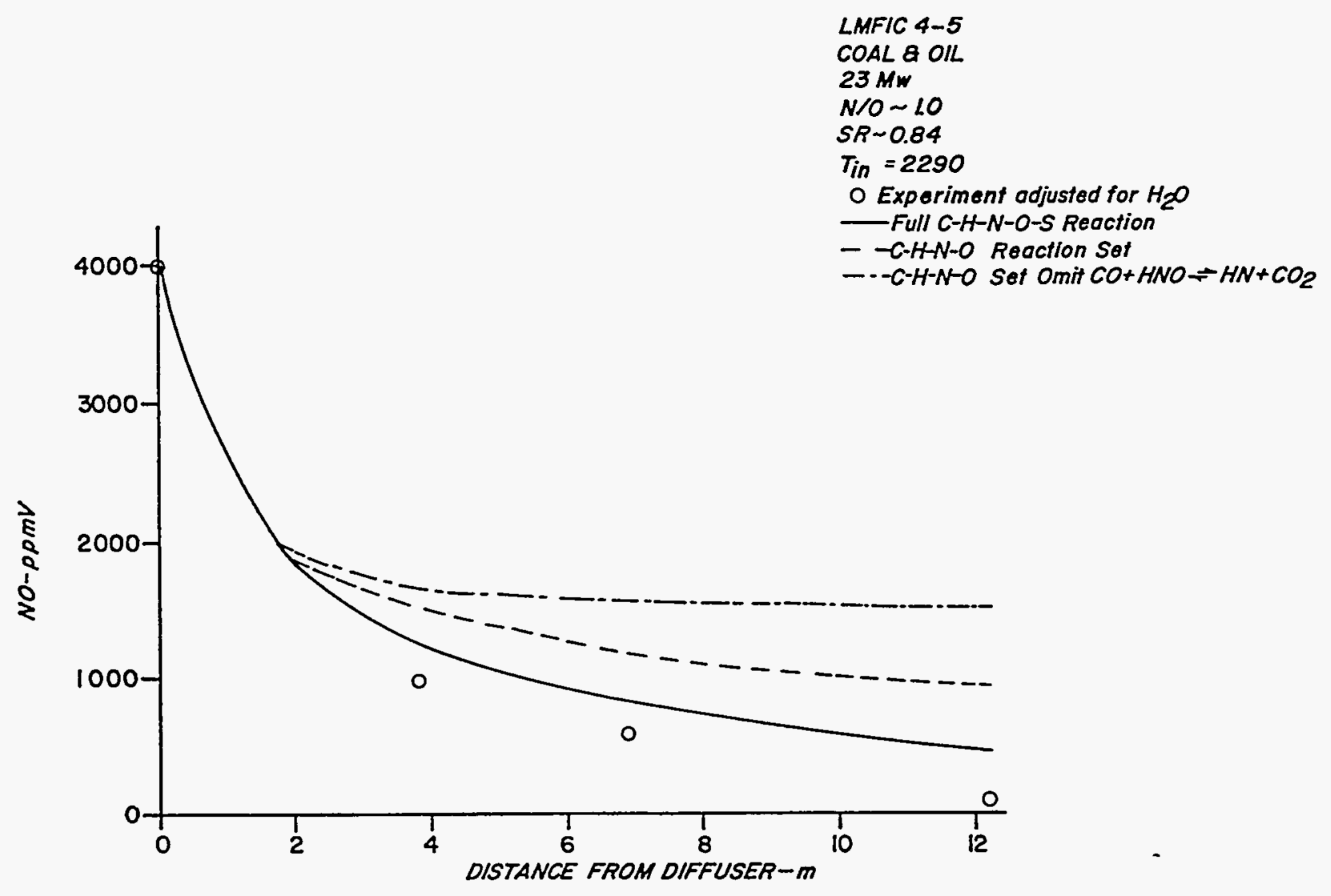

Calculated and Experimental NO Levels in the CFFF Flow Train

Figure 3.2 Calculated and Experimentai NC Leveis in the CFFF Flow Train. 


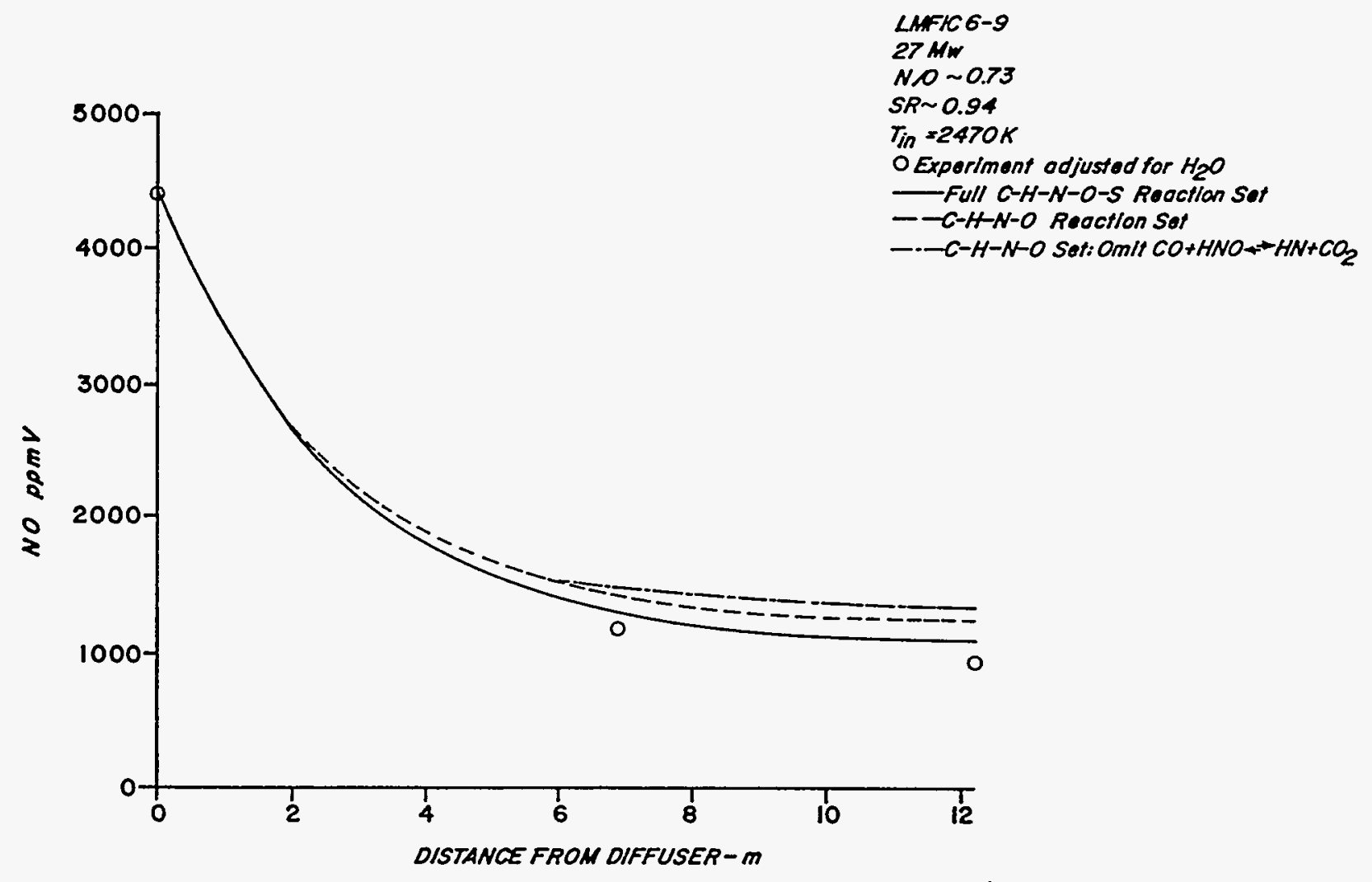

Calculated and Experimental NO Levels in the CFFF Flow Train.

Figure 3.3 Calculated and Experimental No Levels in the CFFF Flow Train. 
This numerical experiment has been repeated by the writers for the combustor conditions of test LMF1-C4 Step 5. At the measured pressure of $0.634 \mathrm{MPa}(6.26 \mathrm{~atm})$ and the computed combustor exit temperature of $2817 \mathrm{~K}$, an equilibrium of the gas phase species was calculated assuming complete combustion. The $\mathrm{NO}$ level was set to be near zero, while $\mathrm{N}_{2}$ and $\mathrm{O}_{2}$ concentrations were correspondingly increased, for input to chemical kinetics calculation at constant temperature and pressure. The NO content reached 50 percent of equilibrium in 0.3 $\mathrm{ms}, 95$ percent in $1 \mathrm{~ms}$, and over 99 percent in $2 \mathrm{~ms}$. Since MHD combustor retention times are much greater than $2 \mathrm{~ms}$, the usual equilibrium assumption appears to be justified. It would be anticipated that equilibration time in the combustor would be inversely proportional to the pressure, for moderate pressure changes at the same temperature and stoichiometry. It would also be anticipated that equilibration would be much slower at much lower temperatures. However, the combustor temperature used was typical to the CFFF and those projected for large MHD plants.

The PROF kinetic calculational model with the reaction set listed in Table 3.1 were validated in the cases cited above and in many subsequent tests. The model should provide a good prediction for the design of coal fired MHD steam power plants. 


\section{CHAPTER 4}

\section{NITROGEN OXIDE EMISSION ISSUES FOR PLANT DESIGN}

The previous chapter discussed the methodology for kinetic calculations of NO decomposition in the radiant furnace. When the NO has decomposed to a suitable low level, the remaining combustibles in the gas need to be oxidized. If this is done at conditions which result in a high temperature in the secondary combustor, additional $\mathrm{NO}_{x}{ }^{*}$ will be generated. There are two design choices that can avoid significant additional $\mathrm{NO}_{x}$ production in the secondary combustor. The first of these is to allow the gases to cool to a sufficiently low temperature that the combustor equilibrium $\mathrm{NO}_{x}$ level will be below desired emission level. The second method is to design the secondary combustor so that little or no temperature rise occurs. This may be done by staging the air addition over space and time while simultaneously removing energy from the gas. It may also be done by recirculating and injecting cooler flue gas from downstream so that no temperature rise occurs. Any of these techniques have a tendency to reduce the combustion efficiency of the secondary combustor and thus tend to increase the emission of carbon monoxide. In addition, if one assumes, as normally done, that all the heat transfer surface from the diffuser outlet to the secondary combustor inlet is refractory covered boiling surface and all the metallic tubes (ITAH, SH, RH, etc.) are downstream of the secondary combustor, there are plant heat balance implications, to the choice of secondary combustor inlet temperature.

\subsection{Parametric Studies20}

It was not possible, in the CFFF, to assign all process variables to have specified values. The furnace is of a fixed size. Changes in stoichiometry affect flow rates and retention times, with changes, for example, in the furnace inlet temperature and the secondary combustor inlet (SCl) temperature. Changes in total thermal input also change retention times and cooling rate, and temperature levels at various places in the whole flow train.

The chemical kinetic calculations mentioned above are carried out in a parametric fashion. (The computer procedure used is described previously.) In the calculations, it was assumed that an MHD facility using Illinois \#6 coal could be operated at a furnace inlet temperature of $3950^{\circ} \mathrm{F}(2450 \mathrm{~K})$, and that one using Montana Rosebud coal would have a furnace inlet temperature of $3750^{\circ} \mathrm{F}(2339 \mathrm{~K})$. Furnace operation, was considered to be at 1 atm (1.013 bar, 101.3 $\mathrm{kPa}$ ). In the program used, a radiation parameter was used to affect the cooling rate, which was not constant, but decreased as temperature decreased. Experience with the chemical kinetic program has shown that at such inlet temperatures. the mixture is very close to equilibrium, hence equilibrium values were used as starting concentrations. At various

"Nitrogen Oxide (NO) is formed almost exclusively in the reducing zone prior to the secondary combustor. After secondary combustion, the $\mathrm{NO}$ may be converted to nitrogen dioxide $\left(\mathrm{NO}_{2}\right)$ with very small quantities of Nitrous Oxide $\left(\mathrm{N}_{2} \mathrm{O}\right)$. The standards for emission of nitrogen oxides are stated in weight of $\mathrm{NO}_{2}$ /unit of fuel input, pounds mass/million BTU of fuel input or nanograms of $\mathrm{NO}_{2}$ /Joule of fuel input. The molecular weight of $\mathrm{NO}_{2}$ is used in the calculation, in effect assuming that all the oxides are converted to $\mathrm{NO}_{2}$. We have called this the emission index in this and other reports. 
radiation parameters, the reacting mixture at two different secondary combustor inlet temperatures was considered to be mixed with sufficient secondary air to achieve an overall stoichiometry of 105 percent, and the mixture was allowed to react while radiation heat transfer occurred. The main part of the oxidation of fuel constituents, such as $\mathrm{CO}, \mathrm{H}_{2}$, and $\mathrm{H}_{2} \mathrm{~S}$, occurred in one or two computational steps, whereupon the secondary combustor outlet (SCO) mixture also started to cool. Some NO could be generated by thermal processes.

Table 4.1-1 shows some of the most significant results. Coal is considered to be burned with an oxidizer containing 38 volume percent $\mathrm{O}_{2}$ (believed to be representative of early retrofit scenarios). Potassium was included as $\mathrm{K}_{2} \mathrm{CO}_{3}$, with 1 mass percent $\mathrm{K}$ in the primary mixture. Various primary stoichiometries were considered, as indicated in the table. $A$ representative Illinois \#6 coal, at 3.4 percent $\mathrm{S}$, was considered to be the fuel for one part of the study, while a Montana Rosebud coal at 0.8 percent $S$ was considered for the other part. In the table, SR1 refers to the primary stoichiometry, SR2 to the secondary stoichiometry. CR refers to an average cooling rate between furnace inlet and secondary combustor inlet, for a secondary combustor inlet (SCl) temperature of $2000^{\circ} \mathrm{F}$ (1366K).

At a given cooling rate for a given sulfur content, primary stoichiometry has a pronounced effect on $\mathrm{NO}_{x}$ emissions, emissions being higher at higher primary stoichiometry. At a given primary stoichiometry, for a given sulfur content, cooling rate has a significant effect on $\mathrm{NO}_{x}$ emissions, emissions being higher at higher cooling rate. Finally, in the table, there is a predicted difference in the $\mathrm{NO}_{x}$ emissions, which are ascribed mainly to the difference in sulfur contents in the flow. These differences are in line with the differences observed in the LMF5 tests described previously, although conditions in the tests are somewhat different, in particular the cooling rate, which is about $900-1300^{\circ} \mathrm{F} / \mathrm{sec}$ in the CFFF, depending on flow rate and primary stoichiometry.

Another issue which has a significant effect on $\mathrm{NO}_{x}$ emissions is the secondary combustor inlet $(\mathrm{SCl})$ temperature. Two factors are involved. The first factor is that by causing mixing at a higher temperature, not as much NO has decomposed as when decomposition is allowed to proceed to a lower temperature. The second factor is that the maximum temperature reached during secondary combustion is higher, since the starting point is higher, hence more NO will be produced thermally for a higher $\mathrm{SCl}$ temperature. These points are illustrated by Figures 4.1-1, 4.1-2 and 4.1-3. In Figure 4.1-1 the temperatures are shown for cooling rates of about $800^{\circ} \mathrm{F} / \mathrm{S}$ over the temperature range from furnace inlet to an $\mathrm{SCl}$ temperature of $2000^{\circ} \mathrm{F}$, for combustion products of the two coals at a primary stoichiometry of 80 percent. The cooling rate for an $\mathrm{SCl}$ temperature of $2300^{\circ} \mathrm{F}$ would be slightly higher, since cooling rate decreases as temperature decreases. There is a dip in each temperature as secondary air is mixed (secondary air is considered to be at $600^{\circ} \mathrm{F}$ ). (By the calculation procedure used, which is one dimensional, mixing is considered to be non-reaction.) As reaction is allowed to continue, the temperature rises abruptly, then drops off when the secondary combustion reaction is essentially complete, and radiation to the walls cools the mixture. Figure 4.1-2 shows calculated $\mathrm{NO}$ contents for the process described (there is negligible $\mathrm{NO}_{2}$ at these conditions). Figure 4.1-3 shows the $\mathrm{NO}_{x}$ emission index for the various flows considered. Because of the assumptions involved, for each coal combustion product, the NO content and $\mathrm{NO}_{x}$ emission index are identical in the high temperature range, prior to secondary combustion for the case of $\mathrm{SCl}$ temperature at $2300^{\circ} \mathrm{F}$. 
TABLE 4.1-1

PARAMETRIC STUDY OF EXIT COOLING RATES IN THE RADIANT FURNACE ON NOX EMISSIONS NOx Illinois \#6 Coal $(3.4 \%$ Sulfur)

\begin{tabular}{|c|c|cc|}
\hline SR & SR & \multicolumn{2}{|c|}{ CR } \\
oF/Sec & $\begin{array}{c}\text { NOx } \\
\text { \#/MMBtu }\end{array}$ \\
\hline .80 & 1.05 & 800 & .050 \\
\hline .80 & 1.05 & 600 & .035 \\
\hline .80 & 1.05 & 400 & .028 \\
\hline .85 & 1.05 & 800 & .105 \\
\hline .85 & 1.05 & 600 & .068 \\
\hline .85 & 1.05 & 400 & .042 \\
\hline .90 & 1.05 & 800 & .240 \\
\hline .90 & 1.05 & 600 & .160 \\
\hline .90 & 1.05 & 400 & .095 \\
\hline
\end{tabular}

Conditions

$$
\begin{gathered}
3950^{\circ} \mathrm{F} \text { - Exit Temperature Diffuser } \\
2000^{\circ} \mathrm{F} \text { - Inlet Temperature Secondary Combustor } \\
\mathrm{NO}_{\mathrm{x}} \text { Rosebud Coal ( } 0.8 \% \text { Sulfur) }
\end{gathered}
$$

\begin{tabular}{|c|c|cc|}
\hline SR & SR $_{\mathbf{1}}$ & \multicolumn{2}{|c|}{ CR } \\
of/Sec & $\begin{array}{c}\text { NO }_{\mathbf{x}} \\
\text { \#/MMBtu }\end{array}$ \\
\hline .80 & 1.05 & 800 & .067 \\
\hline .80 & 1.05 & 600 & .049 \\
\hline .80 & 1.05 & 400 & .038 \\
\hline .85 & 1.05 & 800 & .130 \\
\hline .85 & 1.05 & 600 & .092 \\
\hline .85 & 1.05 & 400 & .060 \\
\hline .90 & 1.05 & 800 & .300 \\
\hline .90 & 1.05 & 600 & .220 \\
\hline .90 & 1.05 & 400 & .140 \\
\hline
\end{tabular}

Conditions

$$
\begin{aligned}
& 3750^{\circ} \mathrm{F} \text { - Exit Temperature Diffuser } \\
& 2000^{\circ} \mathrm{F} \text { - Inlet Temperature Secondary Combustor }
\end{aligned}
$$

NOTE: It is mentioned here that similar effects occur at other stoichiometries and cooling rates. At higher primary stoichiometries, NO generated during secondary combustion is lower than at 80 percent, but the $\mathrm{SCl} N \mathrm{NO}$ content is higher. It turns out that more NO remains in the gas, after secondary combustion, for higher stoichiometries. 


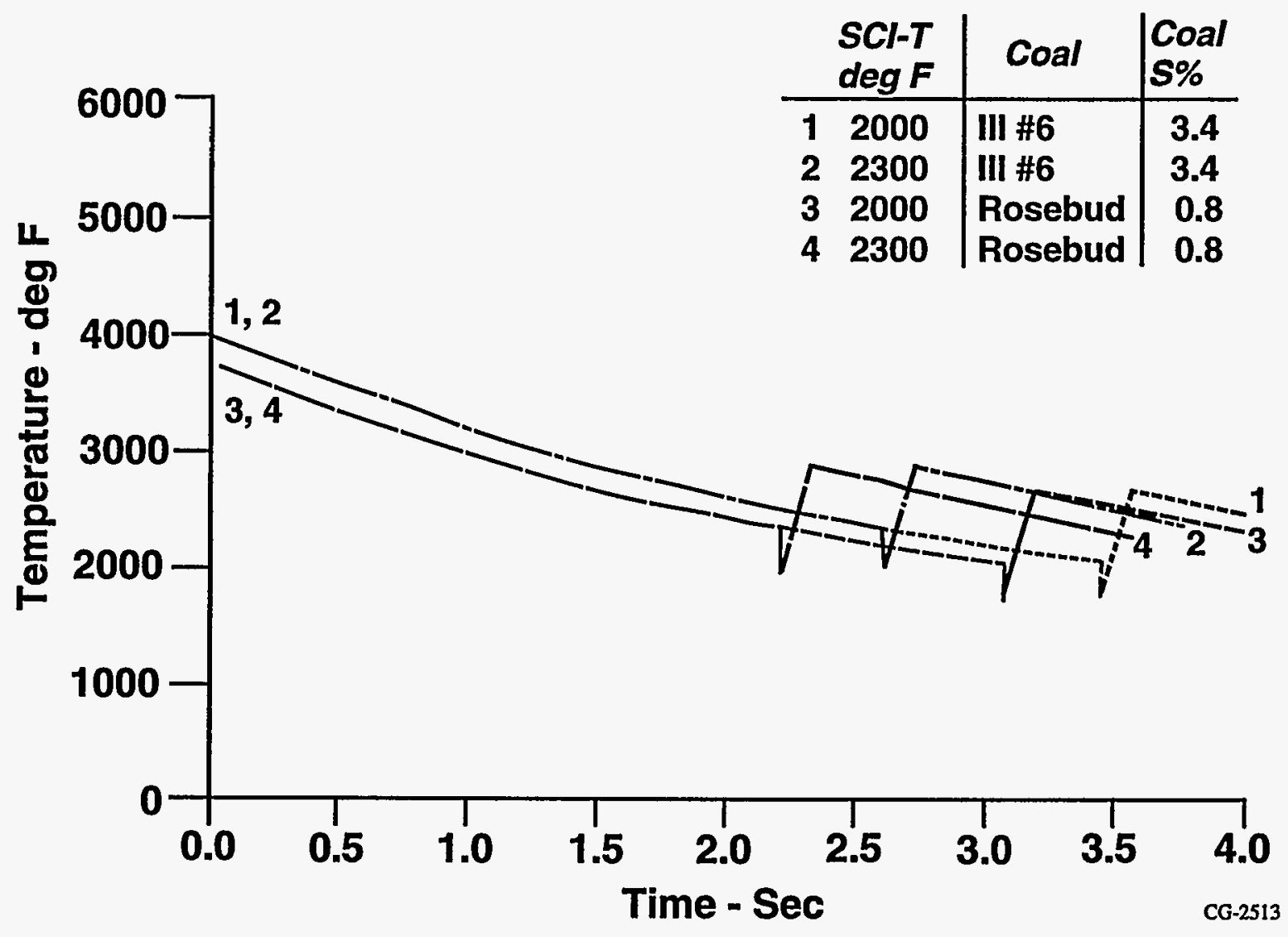

Figure 4.1-1 Parametric Study, $\mathrm{NO}_{\mathrm{x}}$ Emissions, Illinois \#6 and Rosebud Coal Fuels at 85 Percent Stoichiometry, Cooling Rate Approx. $600^{\circ} \mathrm{F} / \mathrm{s}$ Temperature Profiles. 


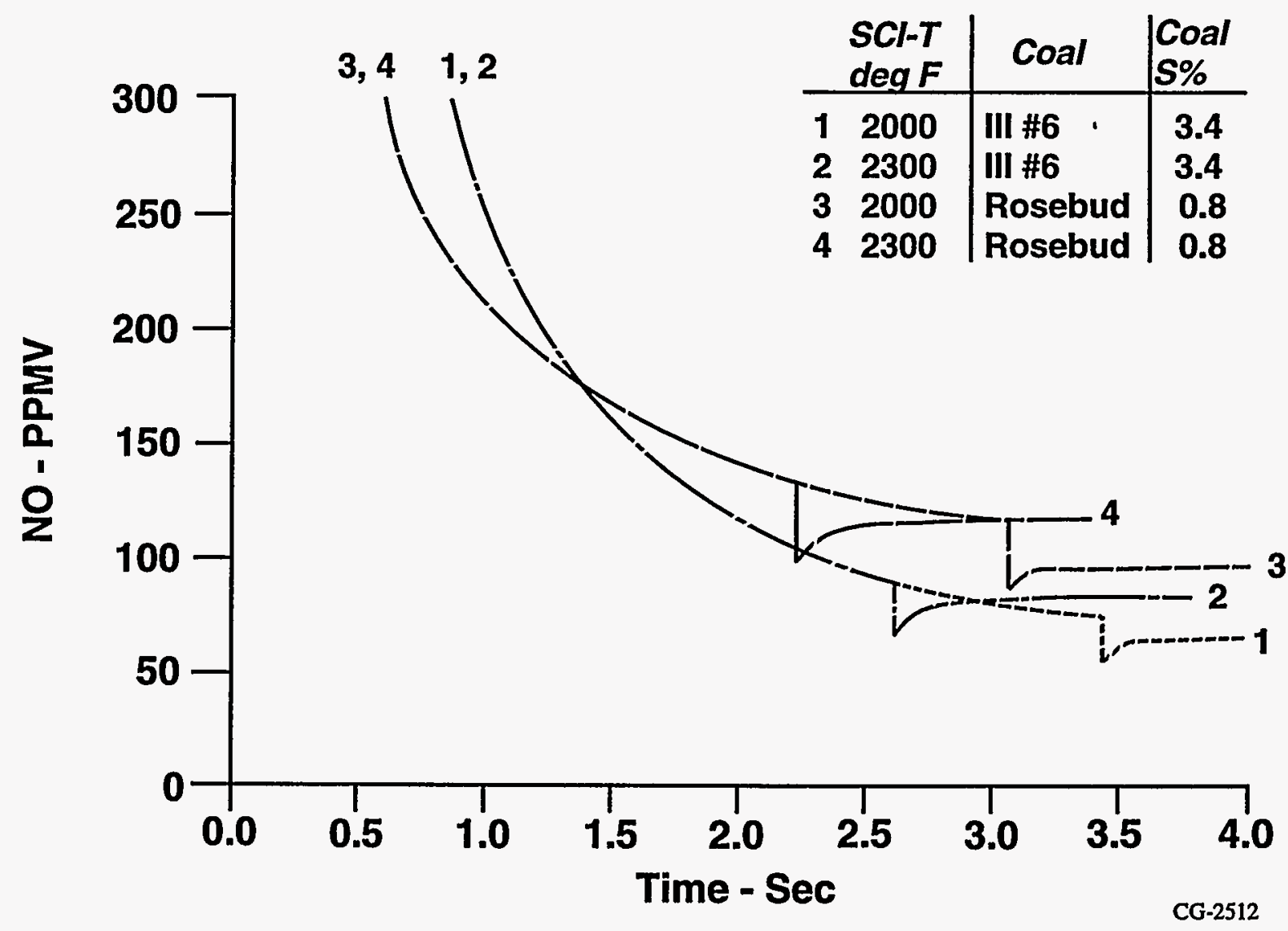

Figure 4.1-2 Parametric Study, NO Emissions, Illinois \#6 and Rosebud Coal Fuels at 858 Primary Stoichiometry, Cooling Rate Approx. $600^{\circ} \mathrm{F} / \mathrm{S}$ - NO Contents. 


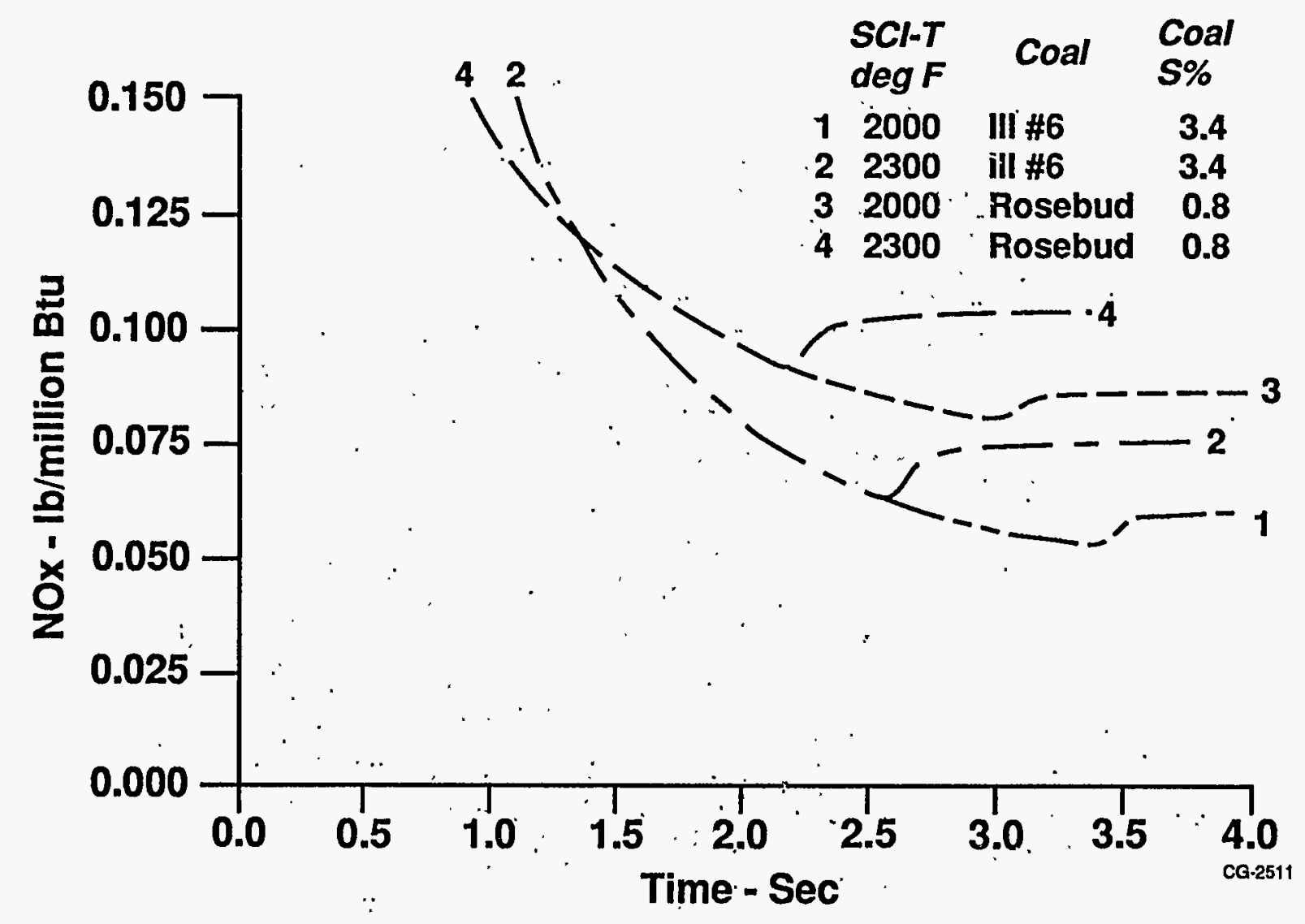

Figure 4.1-3 Parametric Study, NO Emissions, Illinois \#6 and Rosebud Coal Fuels at 85 Percent Primary Stoichiometry, Cooling Rate Approx. 600\%F/S Emission Index. 
While $\mathrm{SCl}$ temperature has a significant effect on $\mathrm{NO}_{x}$ emissions, the furnace inlet (or diffuser outlet) temperature does not have much of an effect, as long as the furnace inlet temperature is above about $2300 \mathrm{~K}\left(3680^{\circ} \mathrm{F}\right)$. At such temperatures, for cooling rates considered here, the NO content is very close to equilibrium.

\subsection{Minimization Study}

As can be noted from Table 4.1-1 and the previous figures, all reasonable design conditions for the MHD Steam Power Plant easily meet the New Source Performance Standards (NSPS) that were in effect during the MHD development program, $0.6 \mathrm{lbm} / \mathrm{MMBtu}$. The Clean Air Act Amendments of 1990 tasks EPA to promulgate more stringent standards and they have suggested that standards as low as $0.15 \mathrm{lbm} / \mathrm{MMBtu}$ may be imposed by the year 2003.21 In addition, some state governments have already proposed limits for new facilities as low as 0.10 $\mathrm{lbm} / \mathrm{MMBTU}$. With this in mind, calculations were performed to find conditions which minimize the $\mathrm{NO}_{x}$ emissions for Rosebud Coal. (The emissions would be somewhat less with a high sulfur coal.) The results for reasonable average cooling rates and secondary combustor inlet conditions are shown in Figure 4.2-1. The $600^{\circ} \mathrm{F} / \mathrm{sec}$ (average cooling rate implies residence times of 2.4 seconds to get to an $\mathrm{SCl}$ temperature of $2300^{\circ} \mathrm{F}$ and 2.9 seconds to get to $2000^{\circ} \mathrm{F}$, but both could be used to meet a $0.1 \mathrm{lbm} / \mathrm{MMBTU}$ standard. If one were willing to build a larger radiant furnace having residence times of 3.6 seconds to get to a $\mathrm{SCl}$ of $2300^{\circ} \mathrm{F}$ or 4.4 seconds for a $\mathrm{SCl}$ of $2000^{\circ} \mathrm{F}$, the plant could operate at a higher stoichiometry and thus a higher efficiency and still meet the $0.1 \mathrm{lbm} / \mathrm{MMBTU}$ emission criterion. Obviously, this is an economic choice between higher capital costs for a larger furnace and the higher efficiency possible with a higher primary stoichiometry. This argument assumes that given control of the size and shape of a radiant furnace that cooling rates as low as $400^{\circ} \mathrm{F} / \mathrm{sec}$ can be realized. In the concept for an advanced technology MHD steam power plant, in which a ceramic tube high temperature air heater extracts energy from the gas in this temperature zone, additional difficulty and/or capital costs may be encountered in designing for these very low gas cooling rates.

\subsection{Multi-Dimensional Modeling}

All of the calculations previously presented are based on one-dimensional flow and heat temperature calculations to get the time-temperature history of the gases for input to the chemical kinetic calculation. In reality, of course, these are both velocity and temperature boundary layers that influence the NO decomposition, especially in the vicinity of the walls when the gas cooling rate is normally higher than in the center of the furnace. A methodology was developed and demonstrated to take these multi-dimensional effects into account.22 The procedure is to make a multi-dimensional calculation, then run the chemical kinetic calculation along streamlines. A typical result for a case calculated in the LMF radiant furnace is shown in Figure 4.3-1. It should be noted that this furnace is very small ( $4 \mathrm{ft}$. by $4 \mathrm{ft}$.) in cross section. The effects of the walls will decrease significantly for larger furnaces, eg. a $40 \mathrm{ft} . \times 40 \mathrm{ft}$. cross section would be the approximate size for a $1000 \mathrm{MW}_{e}$ plant.

\subsection{Conclusions}

The experimental program conducted by UTSI during the MHD POC program, coupled with a validated chemical kinetic calculational methodology provides the tools needed for design of MHD Steam Power plants for prescribed levels of $\mathrm{NO}_{x}$ emissions. 


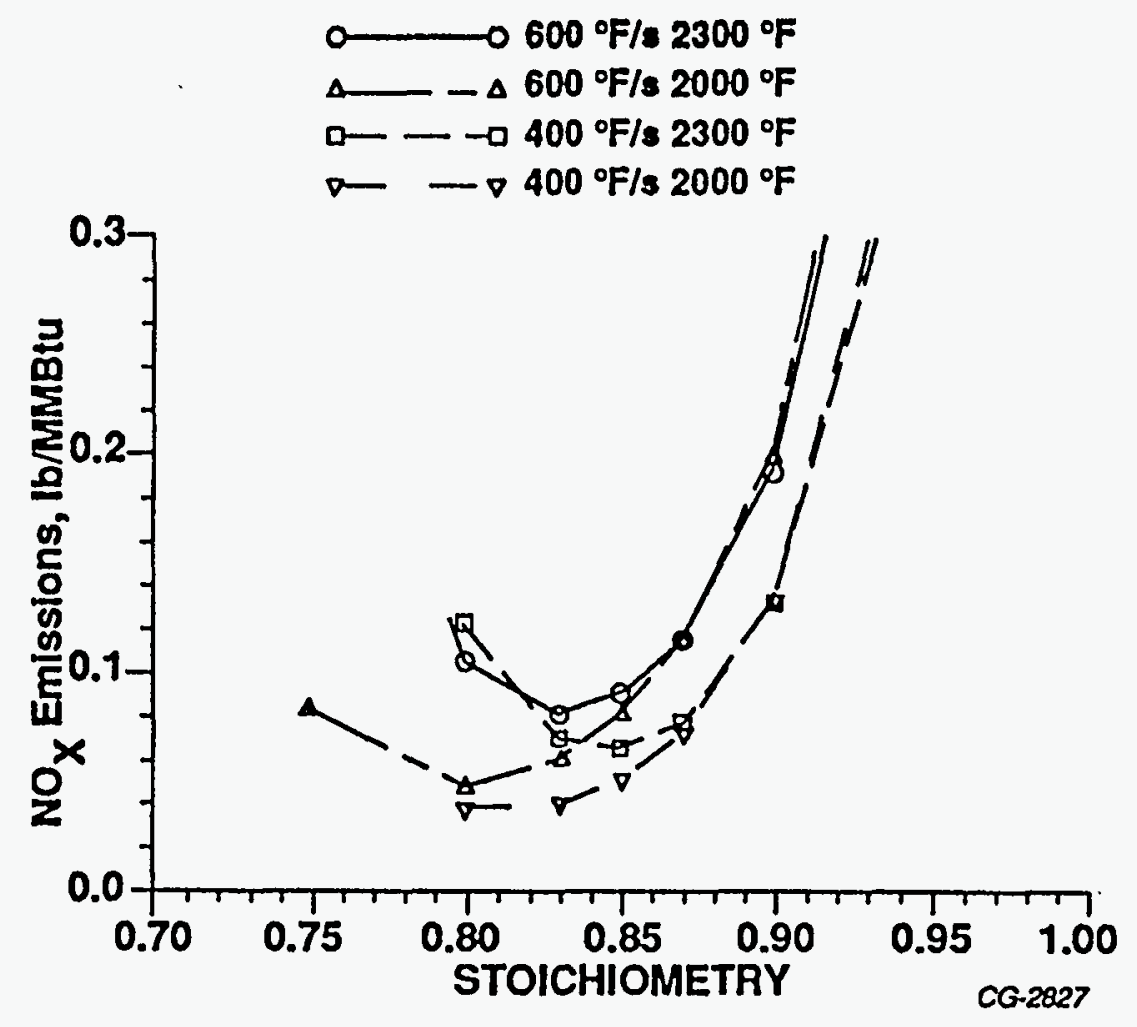

Figure 4.2-1 Effects of Cooling Rate and SCI Temperature on $\mathrm{NO}_{\mathrm{x}}$ Emissions at Various Primary Stoichiometry. 


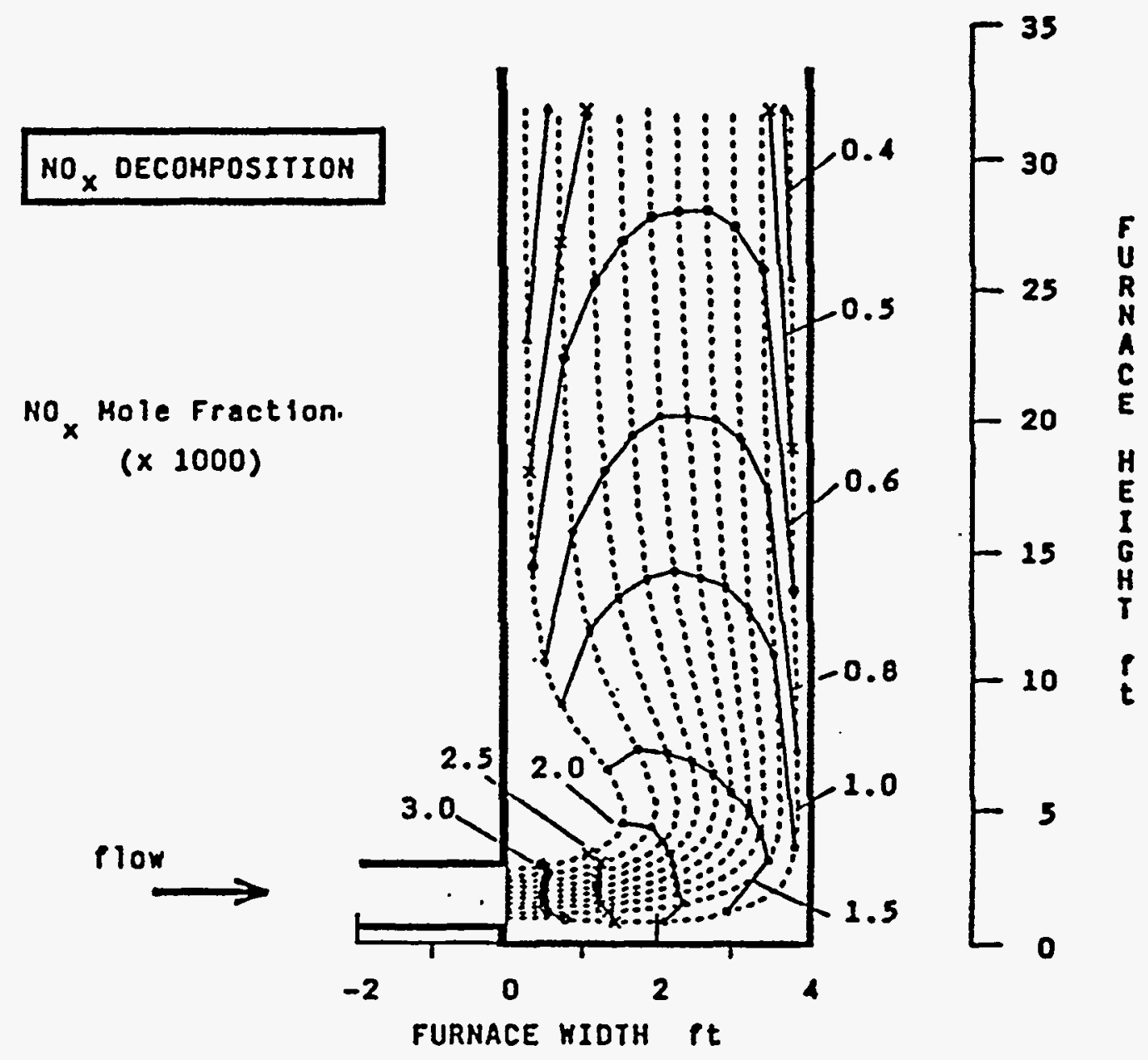

Figure 4.3-1 Spatial Character of Computed CFFF Radiant Furnace NO Decomposition Lines of Constant NO. 
The MHD Steam Power plant can be designed for $\mathrm{NO}_{x}$ emissions of $\mathrm{NO}$ more then .05 $\mathrm{lbm} / \mathrm{MMBTU}\left(22 \mathrm{ng} / \mathrm{Joule}\right.$ ) without auxiliary $\mathrm{NO}_{\mathrm{x}}$ control systems.

Design for $\mathrm{NO}_{x}$ emissions below this level will likely require catalytic reduction.

\section{REFERENCES}

1. "MHD Program Plan", U. S. Department of Energy, DOE/FE-0104, April 1988.

2. Chapman, J. N., "On the Economic Optimization of the Magnetohydrodynamic Steam Power Plant", PhD Dissertation, The University of Tennessee, Knoxville, December 1977.

3. Chapman, J. N. and W. H. Boss, "An Economic Analysis of the Optimum Stoichiometry for An Early Commercial MHD Steam Combined Cycle Power Plant", Report No. DOE-ET10815-137, The University of Tennessee Space Institute, Tullahoma, TN, May 1990.

4. Strom, S. S., J. N. Chapman, J. W. Muehlhauser and J. H. Lanier, "Controlling NO $\mathrm{N}_{\mathrm{x}}$ from a Coal-Fired MHD Process", Proceedings of the 13th Intersociety Energy Conversion Engineering Conference, San Diego, CA, August 1978.

5. Pepper, J. W., "Effect of Nitric Oxide Control on MHD-Steam Power Plant Economics and Performance", SU-IPR Report No. 614, Stanford University, Stanford, CA, December 1974.

6. "Test Report for Series LMF-0 in the DOE Coal Fired Flow Facility", UTSI, DOE Report No. OR-10815-2, January 1983.

7. "Test Report for Series LMF1A \& C in the DOE Coal Fired Flow Facility, UTSI, DOE Report No. OR-10815-9, May 1984.

8. Knisley, Dennis R., "Reaction Kinetics of the Downstream MHD Process Gas Before Secondary Combustion", MS Thesis, The University of Tennessee, Knoxville, December 1985.

9. "Test Report for the LMF3 Series in the DOE Coal Fired Flow Facility", UTSI, DOE Report No. OR-10815-19, September 1985.

10. "Final Test Report for the LMF4-A to E Series in the DOE Coal Fired Flow Facility", UTSI, DOE Report No. OR-10815-21, May 1988.

11. Kendall, R. M., and Kelly, J. T., "Premixed One-Dimensional Flame (PROF) Code User's Manual," Report EPA-600/7-78-172a, August, 1978.

12. Crawford, L. W., et al., "Nitrogen Oxide Control in a Coal Fired MHD System", Proceedings of the 21st Symposium on the Engineering Aspects of MHD, Argonne, IL, June 1983. 
13. Hahn, W. A. and Wendt, J. O. L., "NO ${ }_{x}$ Formation in Flat, Laminar, Opposed Jet Methane Diffusion Flames," Eighteenth Symposium (International) on Combustion, p. 212, The Combustion Institute, 1981.

14. Levy, J. $\mathrm{M}$, et al, "NOx Abatement in Fossil Fuel Combustion: Chemical Kinetic Considerations," EPA-600/7-79/050d, Feb. 1979.

15. Levy, J. M., et al., " $C_{1}$ and $C_{2}$ Chemistry in Rich Mixture, Ethylene/Air Flames," Nineteenth Symposium (International) on Combustion, p. 167, The Combustion Institute, 1982.

16. Corley, T. L. and Bowman, C. T., "Pulverized Coal Combustion: Pollutant Formation and Control," in preparation for EPA.

17. Wendt, J. O. L. Wootan, E. C., and Corley, J. L., "Postflame Behavior of Nitrogenous Species in the Presence of Fuel Sulfur I. Rich, Moist, Co/Ar/ $\mathrm{O}_{2}$ Flames," Combustion and Flame, p. 261, vol. 49 (1983).

18. Glass, J. W. and Wendt, J. O. L., "Advanced Staged Combustion Configurations for Pulverized Coal," Topical Report No. 1, DOE/ET/15184-1152, December, 1981.

19. Kalfadelis, C. D., et al., "Environmental Assessment of a Coal-Fired Open-Cycle MHD Power Plant," Proceedings of the 14th Intersociety Energy Conversion Engineering Conference, vol. II, p. 1923, 1979.

20. Crawford, L. W. and Attig, R. A., "Impact of Process Variables on $\mathrm{NO}_{\mathbf{x}}$ Emissions for Illinois \#6 and Rosebud Coal Fuels in MHD Power Generation", Proceedings of the 30th Symposium on the Engineering Aspects of MHD , Baltimore, MD, June 29-July 2, 1992.

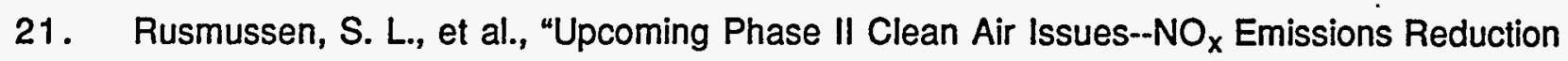
Alternatives and Early Election," Presented at International Power Generation Conference, Minneapolis, MN, October 1995.

22. Crawford, L. W., Lee, J. J. and Lineberry, J. T., "Two Dimensional Modeling of Fluid Mechanics, Heat Transfer and NO Decomposition in the CFFF Radiant Furnacen, Proceedings of the 26th Symposium on the Engineering Aspects of MHD, Nashville, TN, June 1988. 